Article

\title{
Enhanced Compositional Mapping through Integrated Full-Range Spectral Analysis
}

\author{
Meryl L. McDowell ${ }^{1,2, *}$ and Fred A. Kruse ${ }^{2,3}$ \\ 1 Science Applications International Corporation (SAIC), 12010 Sunset Hills Rd., Reston, VA 20190, USA \\ 2 Remote Sensing Center, Naval Postgraduate School, 833 Dyer Rd., Monterey, CA 93943, USA; \\ kruse@hgimaging.com \\ 3 Physics Department, Naval Postgraduate School, 833 Dyer Rd., Monterey, CA 93943, USA \\ * Correspondence: Meryl.L.McDowell@saic.com or mlmcdowe@nps.edu
}

Academic Editors: Naser El-Sheimy, Zahra Lari, Adel Moussa, Gonzalo Pajares Martinsanz, Clement Atzberger and Prasad S. Thenkabail

Received: 14 May 2016; Accepted: 5 September 2016; Published: 15 September 2016

\begin{abstract}
We developed a method to enhance compositional mapping from spectral remote sensing through the integration of visible to near infrared (VNIR, $\sim 0.4-1 \mu \mathrm{m}$ ), shortwave infrared (SWIR, $\sim 1-2.5 \mu \mathrm{m}$ ), and longwave infrared (LWIR, $\sim 8-13 \mu \mathrm{m}$ ) data. Spectral information from the individual ranges was first analyzed independently and then the resulting compositional information in the form of image endmembers and apparent abundances was integrated using ISODATA cluster analysis. Independent VNIR, SWIR, and LWIR analyses of a study area near Mountain Pass, California identified image endmembers representing vegetation, manmade materials (e.g., metal, plastic), specific minerals (e.g., calcite, dolomite, hematite, muscovite, gypsum), and general lithology (e.g., sulfate-bearing, carbonate-bearing, and silica-rich units). Integration of these endmembers and their abundances produced a final full-range classification map incorporating much of the variation from all three spectral ranges. The integrated map and its 54 classes provide additional compositional information that is not evident in the VNIR, SWIR, or LWIR data alone, which allows for more complete and accurate compositional mapping. A supplemental examination of hyperspectral LWIR data and comparison with the multispectral LWIR data used in the integration illustrates its potential to further improve this approach.
\end{abstract}

Keywords: near infrared; shortwave infrared; longwave infrared; thermal infrared; multi-sensor; fusion; data integration; hyperspectral; classification; remote sensing

\section{Introduction}

Spectral remote sensing can be a powerful tool for the characterization of surface composition, particularly when the area of interest is inaccessible, large, in need of repeated examination, or requires rapid evaluation. The advantages of spectral remote sensing have been demonstrated for a wide range of materials and purposes, such as geological mapping, mining and geothermal exploration, vegetation and environmental studies, gas emission monitoring, urban mapping, and anomaly detection, e.g., [1-5]. The majority of the previous work exploiting spectral data has focused on data from a single wavelength range, typically either the visible to near infrared (VNIR, $\sim 0.4-1 \mu \mathrm{m}$ ), shortwave infrared (SWIR, $\sim 1-2.5 \mu \mathrm{m}$ ), or longwave infrared (LWIR, also known as thermal infrared, $\sim 8-13 \mu \mathrm{m}$ ). This common practice may limit the usefulness for many applications where a variety of surface materials are of interest. Because the spectral features in each wavelength range differ based on materials' physical and chemical properties, one range may be well suited for analysis of some materials but provide ambiguous or no information about others. If spectral data from the different 
wavelength ranges are considered jointly, however, they may provide complimentary information that improves the capabilities of the technique.

Few studies of surface composition have taken advantage of data from the full (complete) VNIR, SWIR, and LWIR spectral range. Though they show the added information to be beneficial, most of these investigations have analyzed and interpreted the different spectral ranges separately, e.g., [6-15], not actually combining full-range information into a single integrated data product. By incorporating a data integration step into compositional analysis, spectral (and possibly spatial) associations or patterns may be revealed that have not been considered previously or are too complex to be readily apparent when comparing spectral analysis results by hand. Previous research exploiting integrated VNIR-SWIR-LWIR data has shown its promise and revealed aspects that could be improved. Some of the work has been limited by a single thermal band [16], multispectral (i.e., a few spectral bands, 1-10) VNIR-SWIR imagery [17,18], or no inclusion of VNIR bands [19]. A few studies have been complicated by decreased accuracy for some classes dependent on spectral character and classification algorithm employed [20]. Many of the analyses have used per pixel classification requiring training data, e.g., [21] or extensive independent knowledge of the region to be characterized [22,23]. Methods incorporating sub-pixel mixing are likely more realistic interpretations of remote sensing data, but these may still require outside knowledge of the mixing components, e.g., [24]. The most recent studies introduce hyperspectral (i.e., numerous narrow spectral bands) LWIR data into the full-range integrated analysis $[23,25,26]$.

The objective of the current study is to enhance the identification and mapping of surface composition by integrating data from the full VNIR-SWIR-LWIR spectral range. Our approach consists of two stages; in the first stage we perform spectral analysis on the data from each wavelength range independently, and in the second stage we integrate the resulting independent compositional information to produce a final full-range classification map. The decision to implement integration in the second stage using the results of the independent analyses rather than the spectra themselves was motivated by a desire to preserve the original accuracy achievable for each of the traditional spectral regions and improve upon it with the incorporation of the complementary information. This approach also avoids any bias that might be introduced into the combined data by joining spectra with disparate absolute values and spectral resolutions.

As our primary focus is on data integration, a variety of spectral analysis methods could be used in conjunction with this approach. We chose to employ a partial unmixing method with mixing components derived from the data themselves, requiring minimal outside knowledge of the scene [27]. We use hyperspectral VNIR-SWIR imagery and multispectral LWIR imagery, as these are commonly available. Hyperspectral LWIR imagery has potential benefits beyond those of multispectral LWIR imagery [28], but those data are just now becoming more readily available. We are fortunate to have a supplementary hyperspectral LWIR data set from a portion of the study region and provide selected examples of the differences between multispectral and hyperspectral LWIR data, illustrating the capacity for even greater advancement of this technique.

\section{Data Sets and Methods}

\subsection{Study Site}

We applied our approach to a region along the California-Nevada border centered near Mountain Pass, California (Figure 1). The study area is approximately $2200 \mathrm{~km}^{2}$. Interstate 15 runs east-west across the region. It is a rural desert environment composed of unconsolidated sediments, rock, sparse vegetation, and a small number of manmade surfaces and structures. These include the Mountain Pass mining facility, Ivanpah Solar Power Facility, Primm Valley Golf Club, and the city of Primm, Nevada. The local vegetation consists of several types of trees, bushes, and grasses, such as creosote bush, Joshua Tree, blackbrush, white bursage, yuccas, catclaw, mesquite, rabbitbrush, desert willow, smoke tree, sagebrush, single leaf pinyon and white fir [29,30]. Mars and Rowan [30] suggest that 
vegetation covers $20 \%-35 \%$ of the surface in the area around Mountain Pass. Several mountain ranges cross the region, interspersed with sediment-covered valleys, some of which contain playas or dry lakes [29].

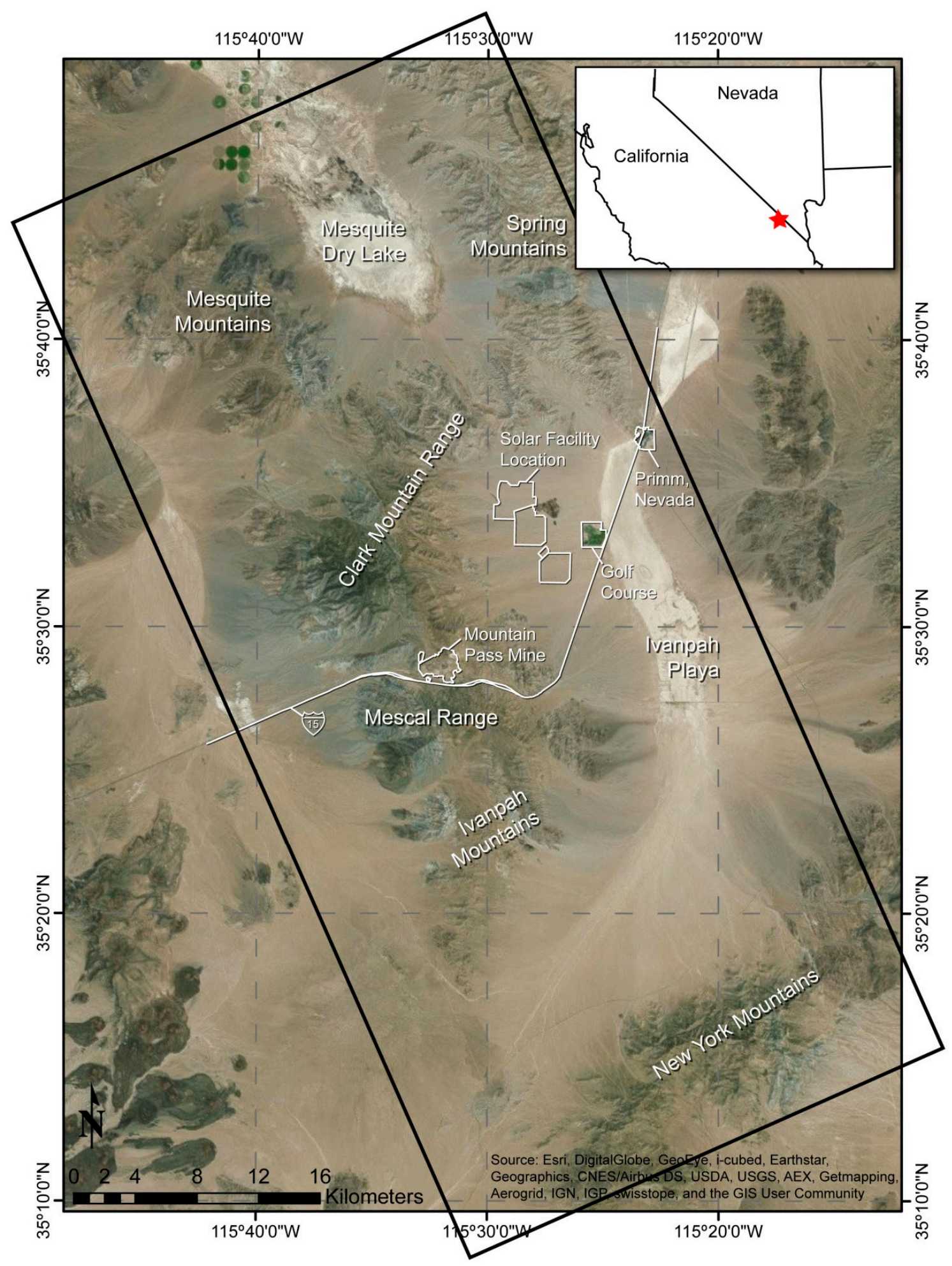

Figure 1. The region near Mountain Pass, California. The basemap image is from the ArcGIS Online World Imagery basemap by Esri. The solid black outline gives the approximate extent of the study area covered by the spectral imagery. Significant terrain features are labeled. Note that the Solar Facility location is marked but not visible in the image, which was acquired pre-construction. 


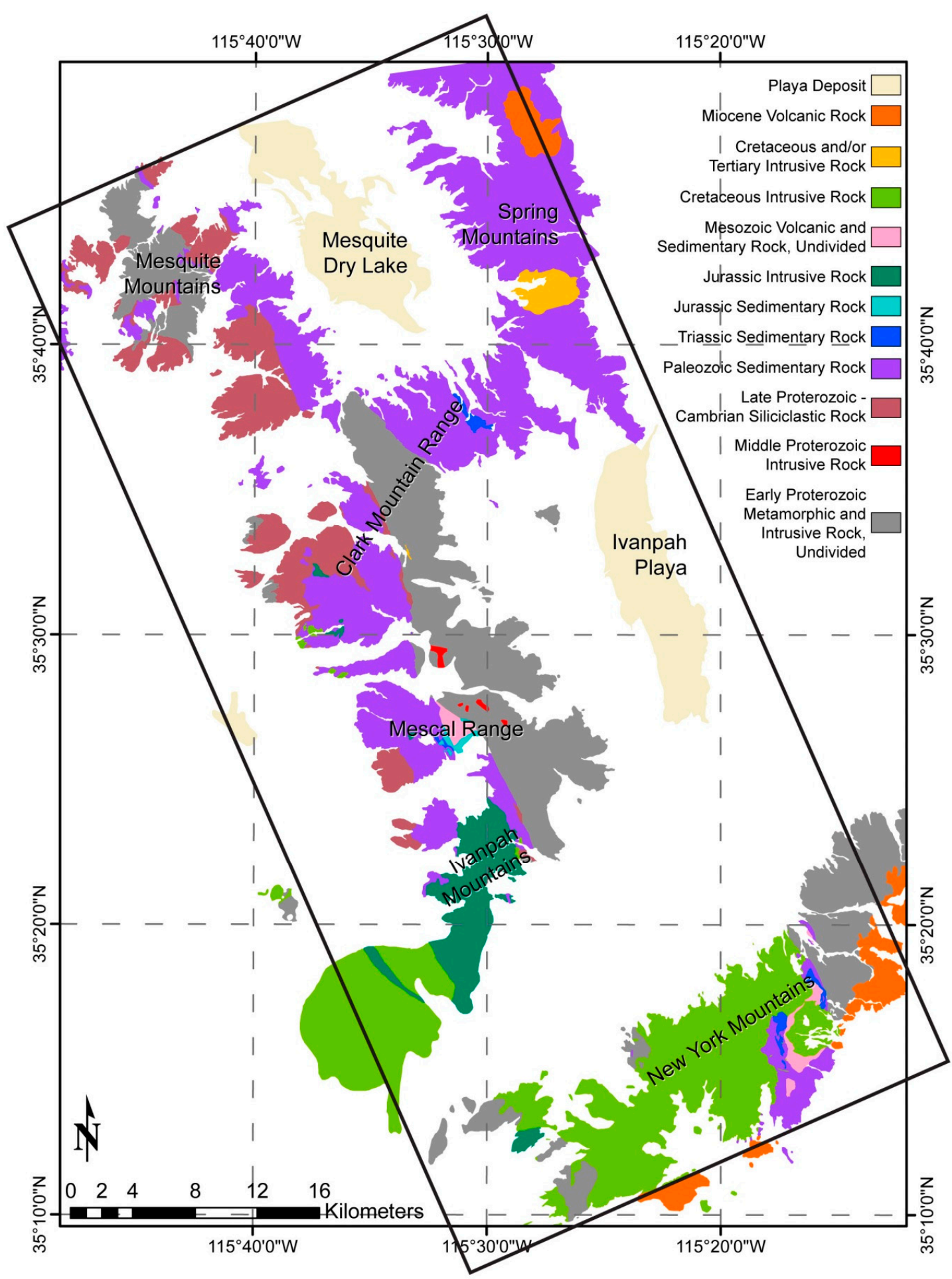

Figure 2. Simplified surface geologic map indicating general lithology and notable features, based on the surficial and geologic maps of Schmidt and McMackin [29], Miller et al. in [31] and Hewett [32]. The solid black outline gives the approximate extent of the study area covered by the spectral imagery. Uncolored surfaces within the study area represent Quaternary alluvium deposits.

The area is geologically diverse, containing a wide variety of rock types and ages, brought together through numerous intrusive episodes and extensive faulting in the region. Detailed discussions of the lithology and geologic history are given in several reports [29,31-33]; here we provide a general description and simplified surface map (Figure 2) based on these references. Exposures of Early 
Proterozoic (>1600 million years ago) metamorphic and intrusive igneous rocks are widespread in the central, northwest, and southeast parts of the study area. There are multiple occurrences of Middle Proterozoic granitoid intrusions, including some of alkaline and associated rare carbonatite compositions. Siliciclastic rocks, including siltstone, shale, quartzite, and limestone, ranging from Late Proterozoic to Cambrian in age, are found in the western portion of the study area, specifically in the northwest Ivanpah Mountains, southwest Mescal Range, western Clark Mountains, and throughout much of the Mesquite Mountain Range. Paleozoic sedimentary rocks, predominantly limestone and dolomite, are widespread over the study area and comprise most of the Spring Mountains and eastern Clark Mountains. They also occur in the Mesquite Mountains, southwest Clark Mountains, west Mescal Mountains, northwest and north-central Ivanpah Mountains, and south-central New York Mountains. Triassic sedimentary rocks consisting of limestone, calcareous shale, and sandstone units are exposed in a small area in the eastern Clark Mountains and in central parts of the Mescal and New York Mountain Ranges, where they are found with Jurassic sedimentary rocks (quartz-rich sandstone) and other undivided Mesozoic volcanic and sedimentary rocks. The central Ivanpah Mountains are composed of Jurassic-age granitic and dioritic intrusive rocks, which are also in the western New York Mountains and in small spots of the central Mescal and southwest Clark Mountains. Cretaceous-age granitoid intrusive rocks make up the southwest part of the Ivanpah Mountains and the western half of the New York Mountains. Small occurrences are also found in the northeast Ivanpah Mountains and southwest Clark Mountains. Cretaceous and/or Tertiary fine-grained felsite and rhyolite intrusions are exposed in the south-central Clark Mountains and southern Spring Mountains, respectively. The youngest rocks in the study area are volcanics of Miocene age ( 5-23 million years ago) observed in the northern part of the Spring Mountains and eastern New York Mountains.

The Middle Proterozoic carbonatite intrusion near Mountain Pass is a particularly notable feature of the area's geology (Figures 1 and 2). These carbonate-rich intrusive igneous rocks are not common and can contain rare earth element (REE)-bearing minerals of industrial value. The carbonatite exposed at and around Mountain Pass is composed primarily of bastnäsite-barite sövite (i.e., calcite carbonatite); bastnäsite-barite beforesite (i.e., dolomite carbonatite); and mixtures of the two. Bastnäsite is the predominant REE-bearing mineral in the ore-grade rock, but other REE-bearing minerals present in the carbonatite include monazite and parasite [34].

\subsection{Data Sets}

The spectral data used in the integration study were collected on the same day (3 May 2013) by two instruments deployed on an ER-2 aircraft at $\sim 20 \mathrm{~km}$ altitude. The VNIR and SWIR data were provided by the Airborne Visible/Infrared Imaging Spectrometer (AVIRIS) [35], which is a hyperspectral imaging sensor measuring radiance from 0.4 to $2.5 \mu \mathrm{m}$ in 224 spectral channels spaced at $10 \mathrm{~nm}$ intervals. Three overlapping image swaths cover the study area, each at $15.5 \mathrm{~m} / \mathrm{pixel}$ (images f130503t01p00r10, f130503t01p00r11, f130503t01p00r12, available for free download at the Jet Propulsion Laboratory (JPL) AVIRIS website, http:/ /aviris.jpl.nasa.gov/data/get_aviris_data.html). Multispectral LWIR data were supplied by the MODIS/ASTER Airborne Simulator (MASTER) [36] and may be ordered at no cost through the JPL MASTER website (http:/ / master.jpl.nasa.gov/). This sensor measures spectral information in 10 channels from 7.8 to $12.8 \mu \mathrm{m}$, in addition to 25 bands in the VNIR-SWIR and 15 bands in the mid-wave infrared (MWIR) that were not used in this study. We used a single MASTER image at $34.4 \mathrm{~m}$ / pixel (image 1394200_06), which is approximately coincident with the coverage of the AVIRIS imagery of the study area.

We also utilize another LWIR data set for comparisons with the MASTER LWIR data. These supporting data were collected on 24 September 2013 by the Mako [37,38] sensor and provided by the Aerospace Corporation (El Segundo, CA, USA). Mako is an airborne hyperspectral imaging system with 128 spectral bands from 7.6 to $13.15 \mu \mathrm{m}$. The Mako data set covers a subsection of the study region around the Mountain Pass mining facility and consists of 34 crosstrack scans (referred to as "whisks") with $1.4 \mathrm{~m} /$ pixel. 


\subsection{Data Preparation}

To enable characterization of surface composition, the spectral data were transformed from the provided at-sensor radiance to surface reflectance or emissivity through a method of atmospheric correction or compensation. For LWIR data this required an additional step to separate the temperature and emissivity components of the surface radiance. The resulting surface reflectance or emissivity spectra can be compared with reflectance or emissivity spectra derived from other images or measured in the laboratory. Any noise or artifacts in the data were also removed where possible. All data preprocessing and subsequent analysis was conducted using the ENVI software (Harris Geospatial Solutions, Boulder, CO, USA), except where otherwise specified.

\subsubsection{AVIRIS VNIR-SWIR}

We employed the radiative transfer model-based Fast Line-of-Sight Atmospheric Analysis of Spectral Hypercubes (FLAASH) algorithm [39] to retrieve and remove the atmospheric components from the AVIRIS VNIR-SWIR calibrated radiance data thus isolating surface reflectance. Several resources, e.g., [40,41], provide helpful discussions on each element of the algorithm and associated input parameters, which may vary with data properties such as location and season. After initial testing with various parameters, we produced the best results for this specific data set using the mid-latitude summer atmospheric model, the rural aerosol model with an initial visibility estimate of $40 \mathrm{~km}$, the $1135 \mathrm{~nm}$ water feature for water vapor retrieval, and the wavelength recalibration option to resolve any wavelength calibration errors that would introduce spectral artifacts to the results. No polishing was conducted within the FLAASH algorithm. A small number of pixels corresponding to liquid water, clouds, or tall mountain peaks produced errors in water vapor estimation and were masked in the resulting image. Any residual noise or artifacts consistent in the spectra throughout the image were reduced using Empirical Flat Field Optimal Reflectance Transformation (EFFORT) polishing $[42,43]$ with a 10th order polynomial. This stand-alone spectral smoothing algorithm allows for more direction from the user compared to the polishing option available in FLAASH.

A comparison of the average spectra from several regions located within the overlapping sections of the three images showed good agreement, with the exception of slight differences in overall reflectance value or spectral contrast. To minimize any effect these offsets could have on the analysis of the three images combined, the images were adjusted to a common baseline. We applied an empirical line correction $[44,45]$ to the outer two images, adjusting their spectra by using the spectra of the selected shared regions from the center image as reference. The three images were then appended to one another in the ' $y$ ' (or along-track) direction to enable further processing and analyses to be applied simultaneously to all images as one scene.

We refined the AVIRIS VNIR-SWIR reflectance spectra further using ground truth data. Reflectance spectra from one bright and one dark region in the study area were collected with an Analytical Spectral Devices (ASD) spectrometer and contact probe. The spectra and their locations were matched with the corresponding image pixels and an empirical line correction was applied to adjust the image spectra to fit within the constraints of the ground truth data.

\subsubsection{MASTER LWIR}

A different approach to atmospheric compensation was used for the MASTER LWIR data. With only 10 LWIR bands, the specific model-based algorithm applied to the hyperspectral LWIR data (Section 2.3.3) was not feasible. Instead, we employed an alternative, empirical approach, In-Scene Atmospheric Compensation (ISAC) [46,47], which is straightforward and easily accessible in ENVI as the Thermal Atmospheric Correction tool. The ISAC method estimates the effective surface radiance (i.e., combined inherent surface radiance and reflected downwelling radiance) solely from the information contained in the image data. The shape of atmospheric transmittance and upwelling radiance components are identified from a plot of radiance and brightness temperature. 
These components are then scaled using the $11.7 \mu \mathrm{m} \mathrm{H}_{2} \mathrm{O}$ feature to produce quantitative transmittance and upwelling radiance spectra for removal from the surface radiance. The contribution from reflected downwelling radiance remains coupled with the surface radiance, however. The ISAC approach requires the presence of near-blackbody surfaces in the scene, commonly approximated by water or green vegetation, and variations in surface temperature. The atmospheric conditions are assumed to be uniform throughout the scene. We included all pixels in the radiance versus brightness temperature plot regardless of the wavelength producing the highest brightness temperature and derived the best-fit line from the points at the top of the bins, which correspond to the pixels with an emissivity closest to 1 . Atmospheric compensation of these data using other ISAC parameters such as the 'max hit' regression pixel option and normalized regression for scatterplot fitting produced less satisfactory results.

To separate the temperature and emissivity components of the effective surface radiance we used the emissivity normalization method [48], which first uses an assumed fixed maximum emissivity value to calculate the temperature at each spectral band for every pixel, and then selects the highest of the resulting temperatures in each pixel to derive its corresponding emissivity spectrum. For this study we specified a maximum emissivity of 1 , which is a reasonable assumption for the majority of natural surfaces and facilitates comparison with library spectra but may not hold for metallic surfaces. The incomplete removal of the reflected downwelling radiance component from the surface radiance with the ISAC method may cause decreased spectral contrast in the emissivity spectra compared to laboratory or model-derived emissivity spectra.

The MASTER LWIR data exhibited significant line to line noise in two spectral channels from issues relating to the detector during this collect. Our attempts to address this non-systematic noise were unsuccessful, and bands $41(7.8 \mu \mathrm{m})$ and $45(9.67 \mu \mathrm{m})$ were removed from further analysis.

\subsubsection{Mako LWIR}

The first three Mako spectral bands were removed before processing due to excessive noise. Prior to importing the data into ENVI, we determined the surface radiance in the other 125 spectral bands (7.69-13.15 $\mu \mathrm{m})$ with the Fast Line-of-sight Atmospheric Analysis of Spectral Hypercubes-Infrared (FLAASH-IR) [49] algorithm, which is similar to that used for VNIR-SWIR data in its basis on the MODTRAN radiative transfer model but designed to address the additional complexities in the LWIR region (e.g., both emitted and reflected components, radiance dependence on emissivity and temperature). The FLAASH-IR algorithm was applied to each of the 34 Mako whisks separately, isolating and removing the atmospheric transmission, upwelling, and downwelling radiance components. Though the algorithm inherently includes temperature-emissivity separation, we recombined the temperature and emissivity output and retrieved surface emissivity in ENVI with the same emissivity normalization method used in the MASTER LWIR preprocessing (maximum emissivity of 1). As noted previously, the resulting emissivity values from this method are likely inaccurate for some materials that are highly reflective. In the small number of cases $(0.004 \%)$ where this caused undetermined or impossible emissivity values those pixels were masked and excluded from further analysis. Additionally, the same nine lines within each whisk repeatedly displayed large data spikes and were masked as well. The surface spectra commonly exhibit a decrease in emissivity at wavelengths less than $\sim 8.7 \mu \mathrm{m}$ that is an artifact of processing.

\subsection{Independent Spectral Analysis}

The first stage of our approach analyzed the AVIRIS and MASTER spectra from each wavelength range individually. The AVIRIS data were separated into VNIR $(<1 \mu \mathrm{m})$ and SWIR $(>1 \mu \mathrm{m})$ portions and analyzed separately because the spectral features in the two regions predominantly originate from different physical processes. The spectral bands in the SWIR regions that are completely obscured by atmospheric water vapor (i.e., 1.263-1.483 $\mu \mathrm{m}$ and 1.792-2.067 $\mu \mathrm{m}$ ) were excluded from analysis. No additional modifications were made to the MASTER LWIR data. 
The goal of the independent spectral analysis was to isolate the primary surface components that are distinguishable in each spectral range and map their contributions to the pixels in the scene. A variety of methods for accomplishing these tasks exist. As previously mentioned, the main focus of this study is on the integration and classification of the data (described in Section 2.5), and therefore the specific approach used for spectral analysis is not strictly prescribed. A discussion of the benefits and limitations of each potential procedure is outside the scope of this work, however, and interested readers are referred to review articles such as $[4,50,51]$ for surveys of these methods and further information. For our individual spectral analysis we followed a standardized routine designed to extract and map the contribution of the most spectrally pure pixels (i.e., endmembers) within an image, sometimes referred to as the "spectral hourglass" approach [27]. Techniques to reduce the dimensionality of the data and number of candidate pixels are applied before extracting the image endmembers and mapping their abundance throughout each pixel in the scene. The flow chart in Figure 3 outlines the specific steps of this procedure.

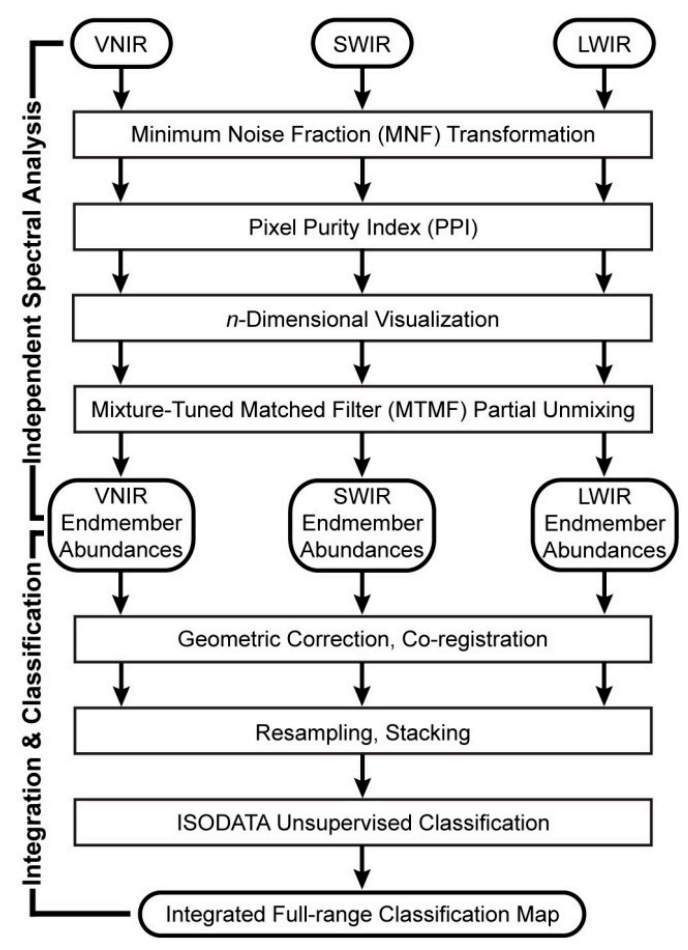

Figure 3. Methods flow chart summarizing the process used in the independent spectral analysis of each wavelength range and the subsequent integration and classification of the resulting endmember abundances. The rounded boxes indicate data products, and the rectangular boxes indicate procedures.

To reduce noise and the spectral dimensions of the data, a Minimum Noise Fraction (MNF) transformation $[27,52]$ was applied to the data of each wavelength range. This transformation is similar to a principal components transformation but orders the components with respect to signal to noise ratio, separating the signal-dominated components from the progressively more noise-dominated components. Only the signal-dominated components were carried forward to the subsequent analysis steps (the exact number of MNF bands varies with the data set).

The number of pixels to be analyzed for endmember extraction was reduced with the Pixel Purity Index (PPI) $[27,53]$. This algorithm creates an $n$-dimensional (n-D) scatterplot of the data and records the number of times a pixel is located on the edge of the data cluster in a series of 2-D projections; the pixels with the highest PPI values are the most unique or pure and possible image endmembers. We used interactive $n$-D scatterplotting $[27,54]$ of the candidate pixels identified by the PPI to extract the final image endmembers. The structure of the data cluster was visualized through repeated 2-D 
projections of the $n$-D scatterplot, and the pixels at the vertices were selected as the image endmembers. This endmember extraction method is based on the concept of the spectral data as an $n$-D simplex where the vertices are pure pixels that combine to form the mixed pixels in the interior. In practice, the image may not actually contain a pixel with the completely pure spectral signature, particularly if the pixel size is large. Instead, multiple pixels with similar spectral signatures but slightly mixed with others would occupy the extremes of the simplex. It is likely that our selection of vertices to represent image endmembers includes some of these slightly mixed pixels, which may result in a larger number of image endmembers than the simplex concept dictates, which is a maximum of $1+$ the number of dimensions (i.e., bands).

To estimate the apparent abundance and distribution of each image endmember, we employed a partial unmixing approach, which can be implemented regardless of whether or not the complete set of image endmembers is known. The Mixture-Tuned Matched Filter (MTMF) algorithm [27,55] (see also [23,56,57]) augments the standard matched filter (MF) output, e.g., [58,59], with an indication of the feasibility of the result given the constraints of physical linear mixtures (i.e., the fractional contribution of all components must be non-negative and sum to 1). From a given target (endmember) spectrum and corresponding background covariance, the MF estimates the endmember's contribution to each unknown spectrum in the scene (i.e., the apparent abundance), referred to as the MF score. Each pixel also has an infeasibility score, which is a measure of the likelihood that its spectrum could be a linear mixture of the endmember spectrum at that abundance and the background distribution. The higher the infeasibility score, the more unlikely is the mixture. For each endmember we used a plot of MF score vs. infeasibility score to determine an appropriate infeasibility score threshold that encompassed the majority of the data cluster but excluded the high infeasibility fringes beyond this background distribution. Figure 4 illustrates this process. For values below this threshold, the corresponding MF score was set as the apparent abundance of that endmember for that pixel; for values above this threshold the abundance of that endmember was set to zero for that pixel. Any MF scores less than zero were also adjusted to zero, and MF scores greater than one were adjusted to one. The result of this independent spectral analysis stage was an image cube for each wavelength range composed of layers of endmember apparent abundance images stacked in the ' $z$ ' direction. These abundance results were then geometrically corrected using flight ephemeris data and carried forward to the second stage of the analysis.

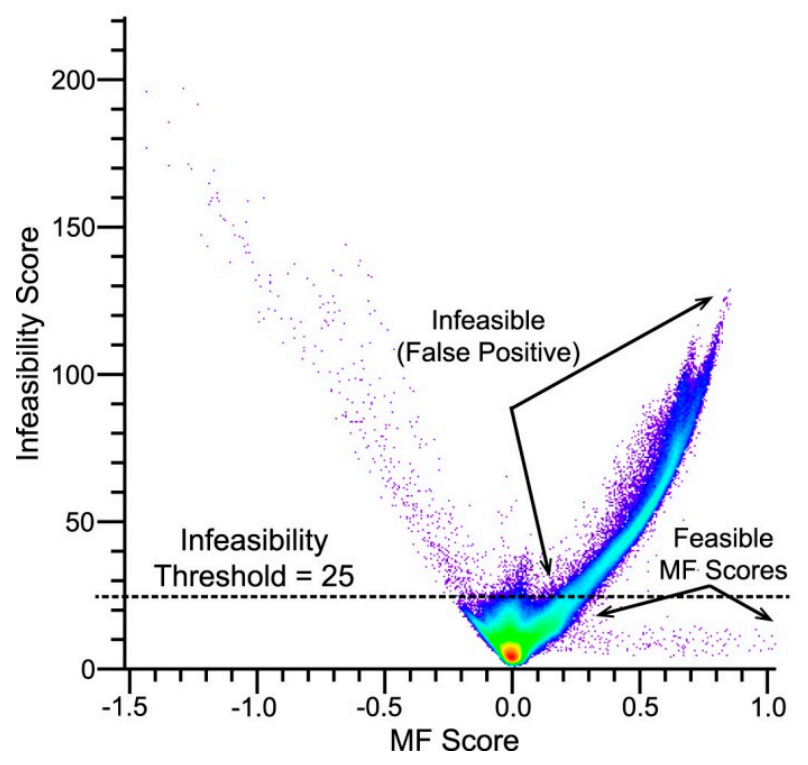

Figure 4. Example of matched filter (MF) score vs. Infeasibility score scatterplot illustrating the selection of an infeasibility threshold at the edge of the data background distribution separating feasible and infeasible MF scores. The class shown here is shortwave infrared Class 2. 
The estimated abundances may be thought of as an indication of the extent to which the endmember spectrum can be used to model the pixel spectrum. At low abundances the endmember spectra have less distinct features and may be considered a plausible component of many pixel spectra where they may not be actually present. From a spot check of endmember abundances and pixel spectra, the abundance value above which the endmembers' contribution or influence was noticeable differed slightly, but a value of $40 \%$ or above appeared to be an appropriate, though perhaps somewhat conservative, estimate for the majority of the endmembers. For the purposes of this work we consider abundance values $\geq 40 \%$ to be significant and limit the presentation and interpretation of the endmember distributions from the individual analyses (Section 3.1) to these significant abundances to avoid over-interpretation.

\subsection{Integration and Classification}

In the second stage of our approach we integrated the AVIRIS VNIR, SWIR, and MASTER LWIR endmember abundance data to produce a full-range classification map. Refined co-registration of the data sets was first performed to reduce errors due to mis-registration in preparation for direct integration. Each of the three AVIRIS VNIR-SWIR abundance images was registered to National Agriculture Imagery Program (NAIP) digital orthorectified imagery at $1 \mathrm{~m} /$ pixel. The corresponding approximate true color RGB AVIRIS images were used to facilitate the selection of tie points. The VNIR and SWIR abundance results were warped using triangulation and nearest neighbor resampling, and then mosaicked together, with the center image (f130503t01p00r10) taking precedence in the overlapping areas.

The MASTER LWIR endmember images were then registered to the VNIR-SWIR mosaic. The large difference in pixel size made registration directly to the NAIP imagery difficult, and accurate co-registration of the LWIR and VNIR-SWIR data sets with one another is the most important goal. Approximate true color RGB versions of the images were again used to help in tie point selection, and warping was done by triangulation and nearest neighbor resampling. We conducted an assessment of the final co-registration error between the LWIR and VNIR-SWIR data sets by generating 100 random points throughout the scene, selecting a test point as near as possible to each random point that could be distinguished in both the VNIR-SWIR and LWIR data and calculating the offset. The registered VNIR, SWIR, and LWIR spectral analysis results were joined by stacking the apparent abundance images in the ' $z$ ' direction, and resampling the data to all have the same $15.5 \mathrm{~m}$ pixel size.

We applied an ISODATA [60] classification to the joined data, which is an unsupervised cluster analysis that iteratively organizes the data into groups based on their position within the data space. This relatively basic method was deliberately selected for this initial study over newer (but likely more complex) techniques in an effort to keep the data integration process and results as simple and straightforward as possible. No training data were needed, and the only specifications were a minimum of 20 and maximum of 200 classes, a minimum of 10 pixels per class, a maximum class standard deviation of 5 digital numbers (DN), a minimum distance between class means of $10 \mathrm{DN}$, and a maximum of 2 merge pairs. The algorithm was limited to 20 iterations with a $7 \%$ change threshold. With this technique we partitioned the input pixels into clusters exhibiting similar endmember abundances throughout the full VNIR-SWIR-LWIR spectral range; the constituent pixels in each of the clusters were designated as a class and displayed to produce a final classification map describing the surface composition.

\subsection{Mako LWIR Examination}

The 34 whisks comprising the Mako emissivity data set were each geometrically corrected with flight ephemeris data and mosaicked together using nearest neighbor resampling. We selected several regions of interest (ROI) to illustrate variations in emissivity spectra that distinguish different compositions at the Mako data's native spectral and spatial resolution, with particular emphasis on materials not readily detectable from the MASTER LWIR multispectral emissivity spectra. Examination 
of the Mako emissivity spectra extracted from the mosaicked configuration assisted in visualization, registration, and comparison with other data sets. To assess the appropriateness of this approach we compared the mean spectra of several of the ROIs from the mosaicked data to the mean spectra of approximately the same regions from the data in their unmodified state prior to geometric correction and mosaicking. Very little, if any, difference was observed between the mean spectra, suggesting that the use of the mosaicked emissivity spectra should not introduce any inaccuracy large enough to be of concern for our intended purposes.

To enable a more direct comparison with the MASTER LWIR multispectral data and analysis of the effect caused by the lower spectral resolution, the Mako emissivity spectra were convolved to MASTER LWIR bandpasses using the instrument's spectral response function for each band. Another modified Mako emissivity data product was created that replicated the larger $34.4 \mathrm{~m}$ pixel size of the MASTER LWIR data. First, to avoid incorporation of the background values assigned to pixels masked in preprocessing due to artifacts, the values of these pixels were replaced using Delaunay triangulation. We then spatially resampled the Mako emissivity mosaic to a pixel size of $34.4 \mathrm{~m}$ using pixel aggregation. The pixel aggregate method most accurately represents the natural sub-pixel mixing effect in which we are interested; the values of the output pixels are area-weighted averages of the input pixels within their boundaries.

\section{Results}

\subsection{Independent Spectral Analysis}

\subsubsection{AVIRIS VNIR}

Independent analysis of the VNIR wavelength range used 14 non-noise MNF bands and found 33 image endmembers. An infeasibility threshold of 20 was applied to the MTMF results of each endmember to produce feasible apparent abundance images.

Several examples of the image endmember spectra are shown in Figure 5. The spectral features of the Classes 6 and 15 endmembers are due to iron oxide minerals, principally goethite. These classes are modeled at significant abundances ( $>40 \%$ ) within a variety of rock units, including metamorphic, granitioid, carbonate, and siliciclastic (Figure 6a). Additionally, the Class 15 endmember is mapped over the cleared surface surrounding several mining sites. The Classes 12 and 33 endmembers both display bright but relatively featureless VNIR spectra that do not allow definitive identification. They are modeled at significant abundances within the region's playa deposits as well as in a few spots in the sedimentary (predominantly carbonate) and siliciclastic units (Figure 6). The distribution of Class 33 also corresponds to the bright soils around many sites of human activity. The VNIR spectrum of the Class 32 endmember is similar to those of Classes 12 and 33 but exhibits a decrease in reflectance near $1 \mu \mathrm{m}$. This feature is consistent with the presence of gypsum, and the high modeled abundances of Class 32 in the gypsum-bearing Mesquite Dry Lake playa deposits support this (Figure 6b). Other materials have similar VNIR spectra, however, and make conclusive identification difficult. The Class 32 endmember is also mapped in a few spots within the Paleozoic sedimentary rock unit.

The majority of the VNIR image endmembers are modeled at significant abundances $(>40 \%)$ only in small discrete areas. From the VNIR spectral features we can identify the presence of green vegetation (e.g., Figure 5, Classes 11 and 17), REE-bearing minerals (e.g., Class 4), and water mixtures (e.g., Class 26-algae and sediment in water, Class 29-REE-bearing minerals in water). Several endmembers exhibit features indicative of manmade materials such as metals and plastics (e.g., Classes 3, 13, 20, 28 and 30). 


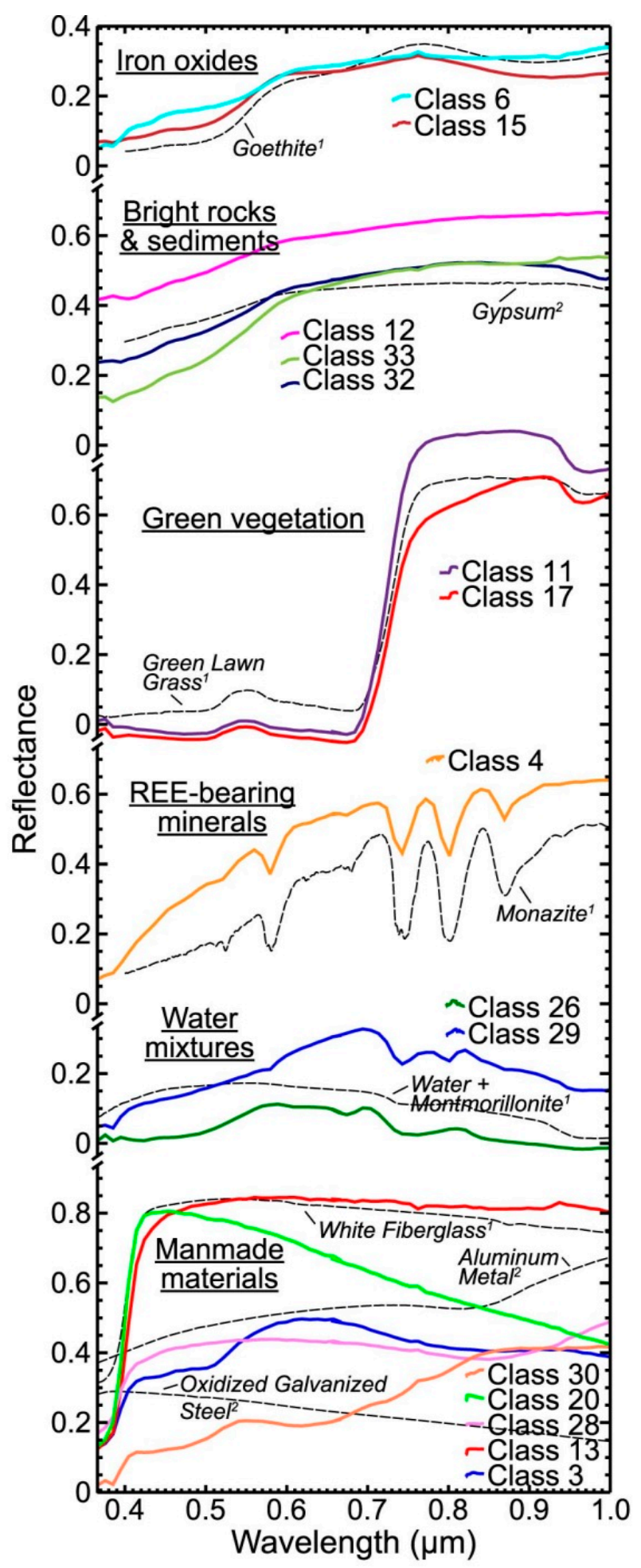

Figure 5. Selected visible to near infrared (VNIR) image endmember spectra and example reference spectra. ${ }^{1}$ USGS Digital Spectral Library [61]; ${ }^{2}$ ASTER Spectral Library [62]. 


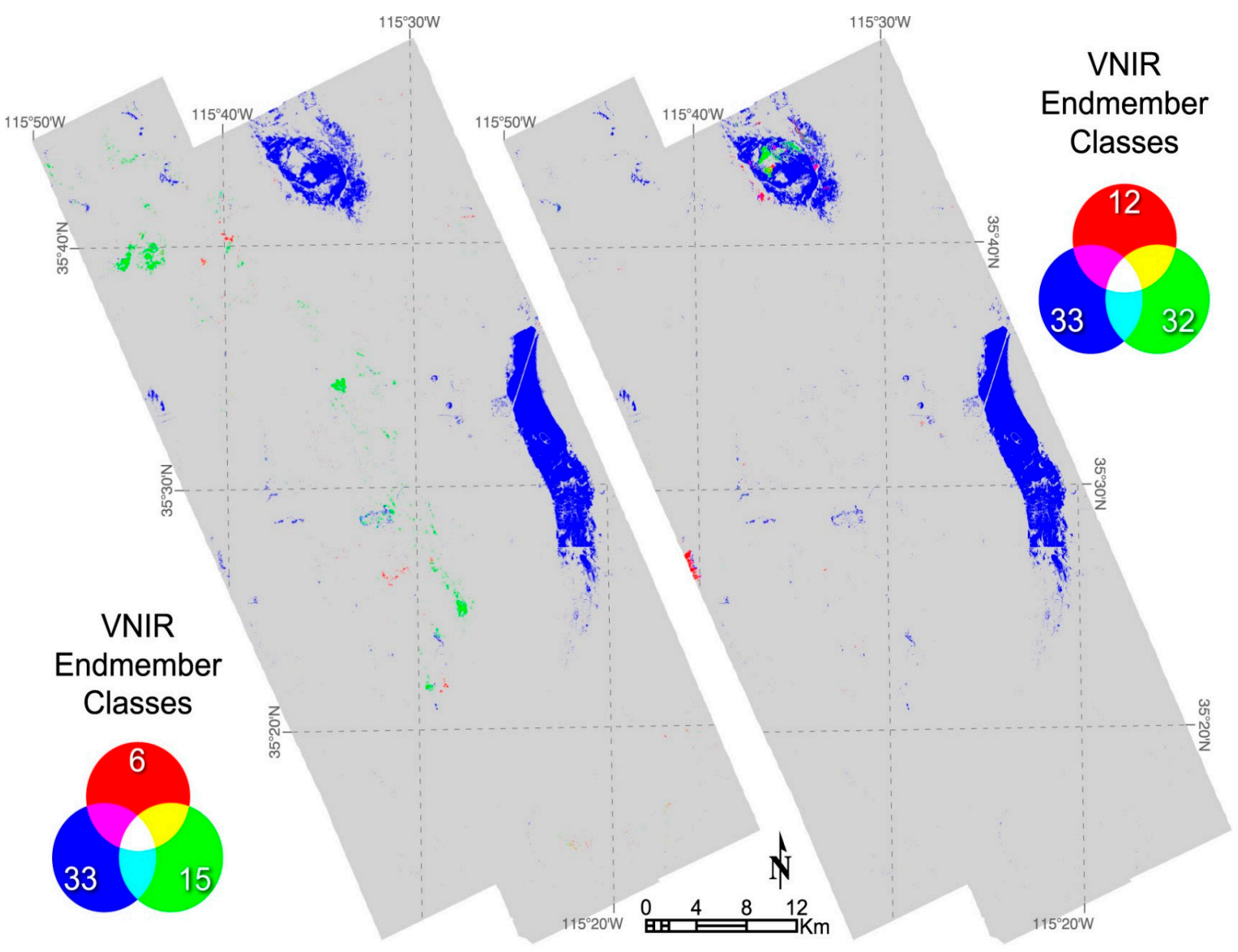

(a)

(b)

Figure 6. False color composite images of selected visible to near infrared (VNIR) endmember classes: (a) 6/15/33 in red/green/blue; (b) 12/32/33 in red/green/blue. Pixels with approximate abundance values less than $40 \%$ for the selected endmembers are masked in gray. 


\subsubsection{AVIRIS SWIR}

The SWIR independent spectral analysis used the first 18 non-noise MNF bands and extracted 48 image endmembers. We refined the MTMF results to include only feasible apparent abundances with an infeasibility score below a threshold of 25 for all endmembers. Several of the image endmember spectra were very similar to one another in spectral features and shape, differing mainly in overall reflectance value. Although these endmembers are statistically different, their material characterization and identification are the same. In these cases, we grouped the similar endmembers into one class and combined their apparent abundance values. This resulted in class abundance values greater than 1 in some instances. Example endmember spectra from several classes are shown in Figure 7.
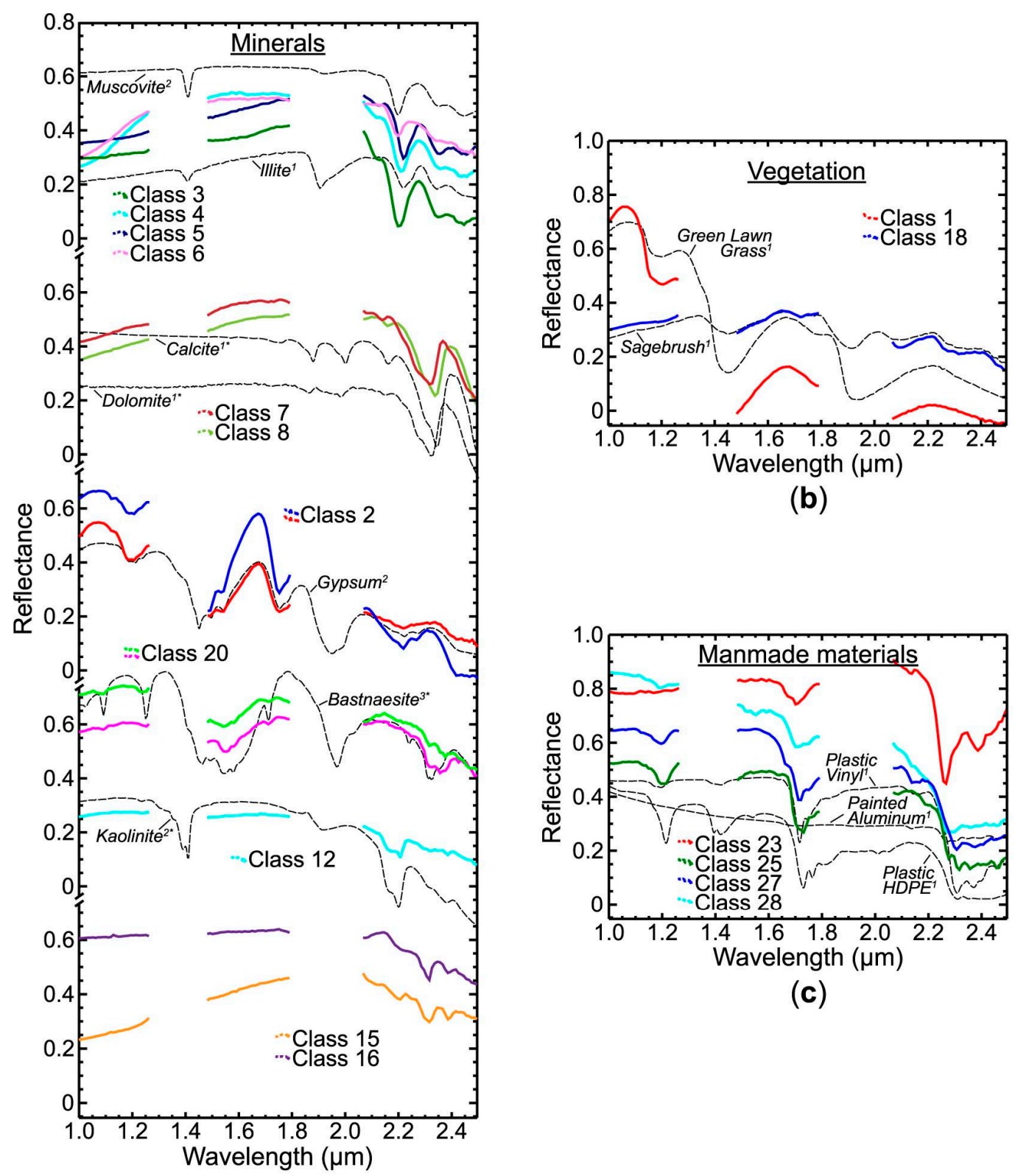

(b)

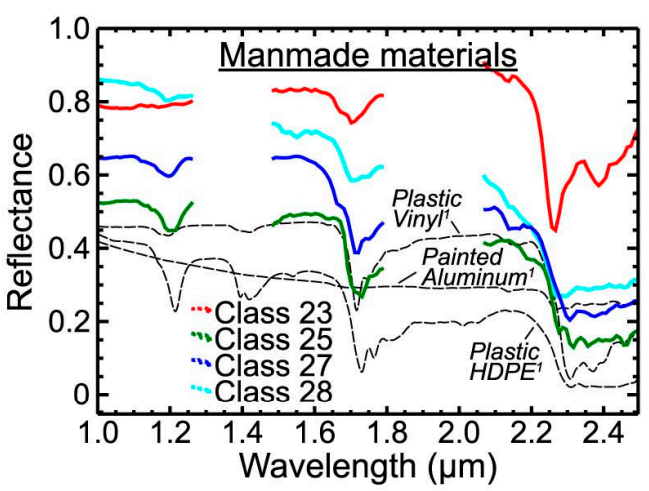

(c)

(a)

Figure 7. Selected shortwave infrared (SWIR) image endmember spectra and reference spectra of: (a) mineral phases; (b) vegetation; (c) manmade materials. ${ }^{1}$ USGS Digital Spectral Library [61]; ${ }^{2}$ ASTER Spectral Library [62]; ${ }^{3}$ Turner et al. [63]. * spectrum has been vertically offset to facilitate comparison and plotting. 


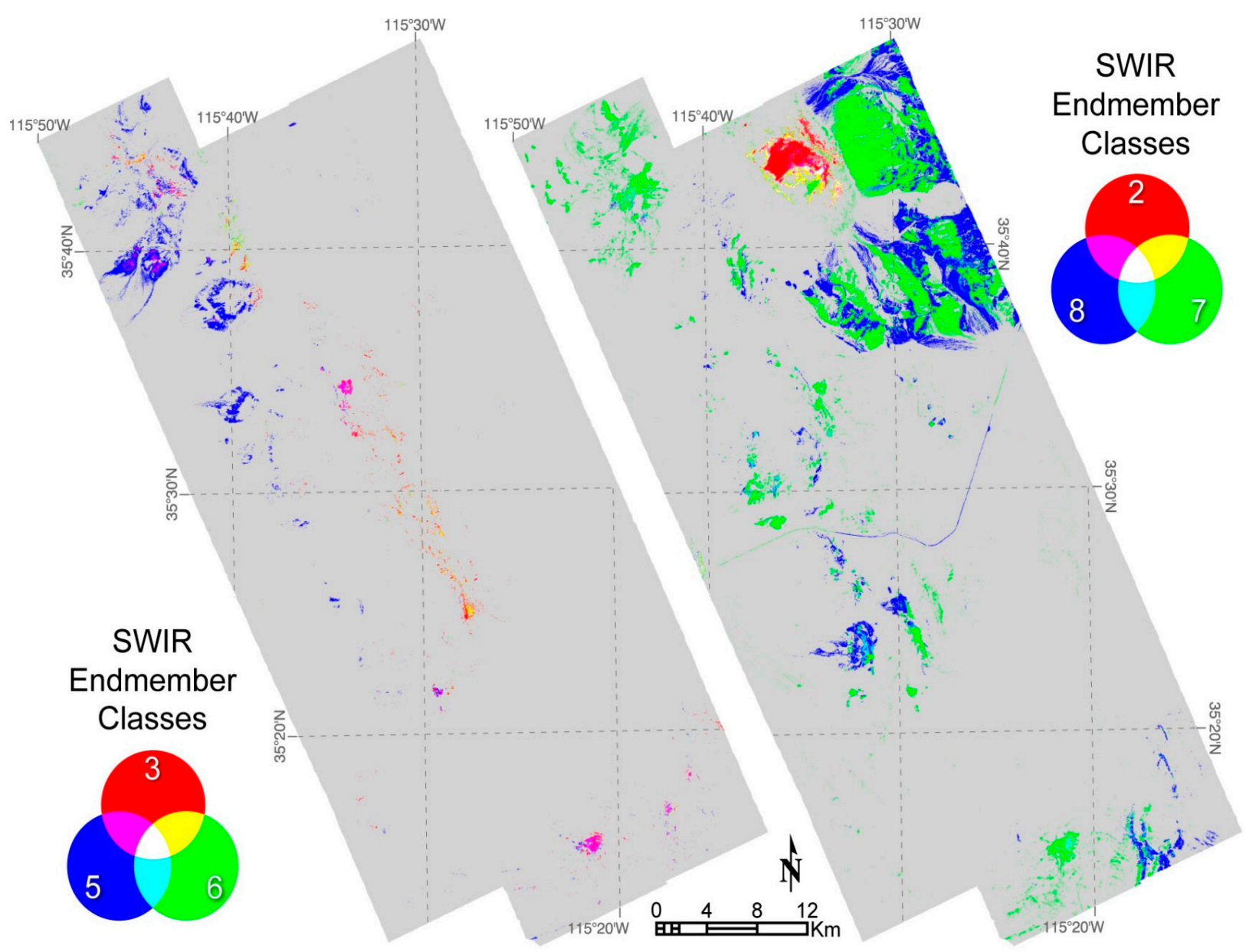

(a)

(b)

Figure 8. False color composite images of selected shortwave infrared (SWIR) endmember classes: (a) 3/6/5 in red/green/blue; (b) 2/7/8 in red/green/blue. Pixels with approximate abundance values less than $40 \%$ for the selected endmembers are masked in gray. 
A few SWIR classes are widely distributed at significant abundances $(>40 \%)$ over the study area and belong to two general mineral categories. The SWIR spectral features of Classes 3, 4, 5, and 6 are indicative of the Al-rich mica minerals muscovite and/or illite, which are indistinguishable at this spectral resolution [64]. Small differences in the exact feature positions between the classes reveal the extent of substitution for aluminum in the crystal structure, e.g., [65,66]; the $\sim 2.2 \mu \mathrm{m}$ minimum of less Al-rich compositions (e.g., Class 5) is shifted to longer wavelengths than the more Al-rich compositions (e.g., Classes 3 and 6). These classes are mapped in areas within metamorphic, granitoid, and siliciclastic rock units, as well as in a few spots in sedimentary units (Figure 8a). They are also modeled in the bare soil areas around some mining sites. The distribution of Classes 3, 4 and 6 are commonly coincident or in close proximity to one another. The distribution of Class 5 differs from the others in that it is mapped within the siliciclastic outcrops and small Cretaceous intrusions in the central part of the study region and not mapped in the central portion of the Early Proterozoic metamorphic unit (Figure 8a). Classes 7 and 8 exhibit the SWIR spectral features of carbonate minerals. Specifically, the position of the feature at 2.316-2.326 $\mu \mathrm{m}$ identifies the presence of dolomite in the Class 7 endmember spectra, and the position of the feature at $2.336 \mu \mathrm{m}$ identifies the presence of calcite (i.e., limestone) in the Class 8 endmember spectra. These carbonate classes are modeled at significant abundances within the Paleozoic sedimentary rock unit, and in spots within many of the other general rocks units, alluvial deposits, and mining sites (Figure 8b). Their distribution also corresponds to some manmade surfaces such as along Interstate 15 and in the solar farm facility. Areas of significant abundance are predominantly modeled as one class or the other, but some overlap does occur. Both classes are mapped within the Mesquite Dry Lake and small western playa deposits, and in these spots it is common for the two classes to be found in the same pixel.

The spectral features of the SWIR Class 2 endmembers are attributed to gypsum, and this class is mapped mainly in the Mesquite Dry Lake playa deposits with smaller areas in the eastern Clark Mountains and the small western playa deposit (Figure 8b). Other classes represent additional mineral phases identified by their spectral features, including kaolinite (Class 12) and REE-bearing bastnäsite and monazite (Classes 20 and 21). The identification of a few SWIR endmember spectra is not straightforward, and they are thought to be complex intimate mixtures or mixtures of components with ambiguous features. For example, the Class 15 endmember spectrum could represent the mixture of a mineral like chlorite, phlogopite, actinolite, or richterite with one exhibiting a $2.2 \mu \mathrm{m}$ spectral feature such as muscovite.

The endmember spectra in Class 1 (Figure 7b) represent green vegetation and are mapped in areas of dense green foliage. The spectral features of Class 18 are also from vegetation, but are more consistent with dry grass, sagebrush, or tumbleweed. Several of the endmember spectra indicate the presence of manmade materials such as plastic vinyl, PVC, HDPE, and aluminum, and their distributions correspond to manmade structures and surfaces (e.g., Classes 14 and 22-28) (Figure 7c).

\subsubsection{MASTER LWIR}

Analysis of the MASTER LWIR data isolated four non-noise MNF bands and resulted in 28 image endmembers. No single infeasibility threshold was appropriate for all endmembers, so the best threshold value to separate the feasible abundances was applied on an individual basis and varied from 5 to 8 . With only 8 spectral bands available definitive identification of the image endmembers is difficult. The endmember spectra do exhibit distinct variations from one another, however, as illustrated in Figure 9.

The Class 1 endmember spectrum has an emissivity minimum in the $8.62 \mu \mathrm{m}$ band, which is consistent with gypsum and supported by the distribution of the endmember at significant abundance in the gypsum-bearing Mesquite Dry Lake playa deposit. The emissivity minimum at $11.33 \mu \mathrm{m}$ in the Class 10 endmember spectrum may reveal the presence of carbonate minerals. In support of this, Class 10 is mapped at significant abundances in the Paleozoic sedimentary (predominantly carbonate) units in the central and northwestern parts of the study region, as well as in the alluvial deposits south 
of the New York Mountains and a few spots in Mesquite Dry Lake (Figure 10a). The low emissivity in the $8.18,8.62$, and $9.06 \mu \mathrm{m}$ bands of the Class 3 endmember spectrum suggests a silica-rich material, as does the class distribution in a large portion of the siliciclastic rock units, their alluvial deposits, and the Jurassic quartz-rich sandstone in the Mescal Range (Figure 10a).

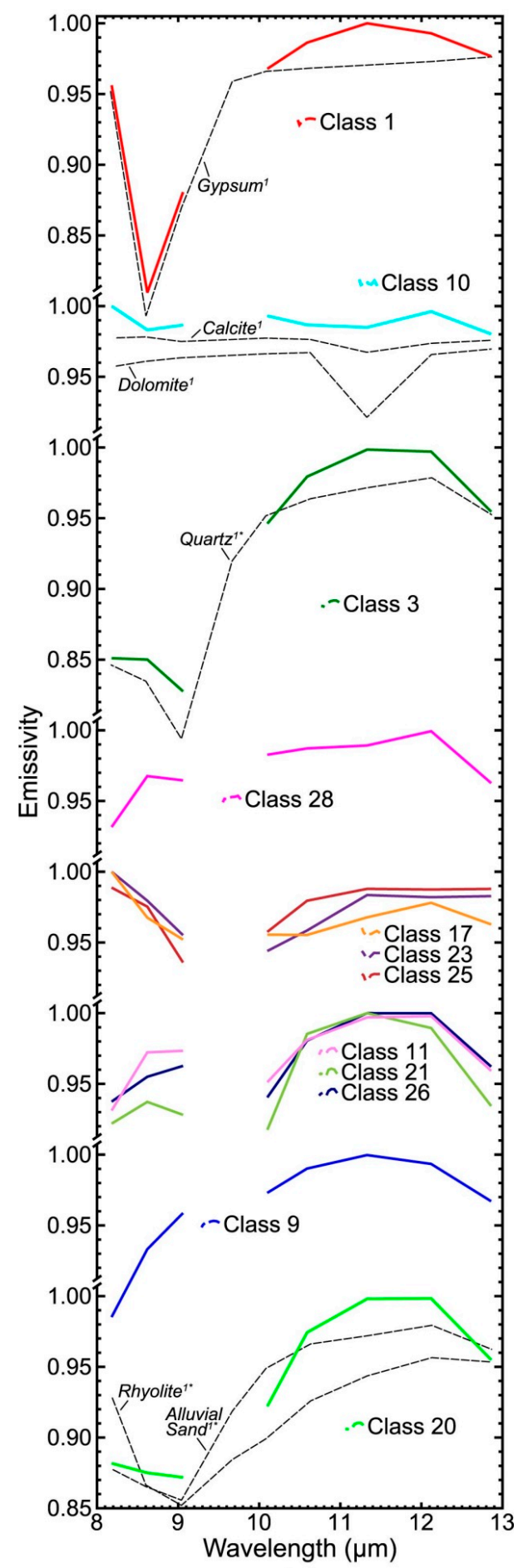

(a)

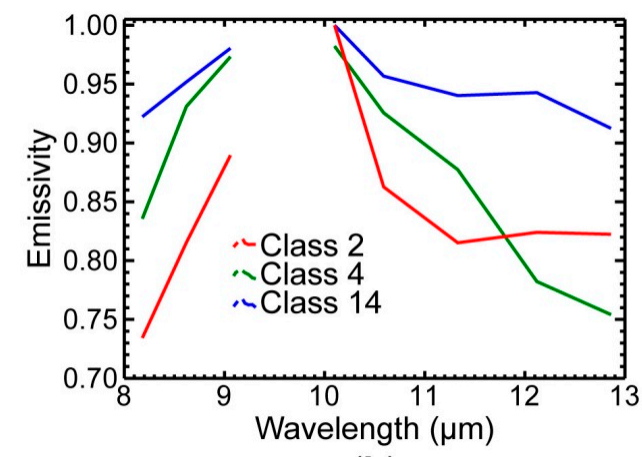

(b)

Figure 9. Selected longwave infrared (LWIR) image endmember spectra modeled predominantly in areas of: (a) natural terrain; (b) manmade surfaces, and example reference spectra convolved to the MODIS/ASTER Airborne Simulator (MASTER) bandpasses. ${ }^{1}$ ASTER Spectral Library [62].

* spectrum's vertical scale has been decreased to facilitate comparison and plotting. 


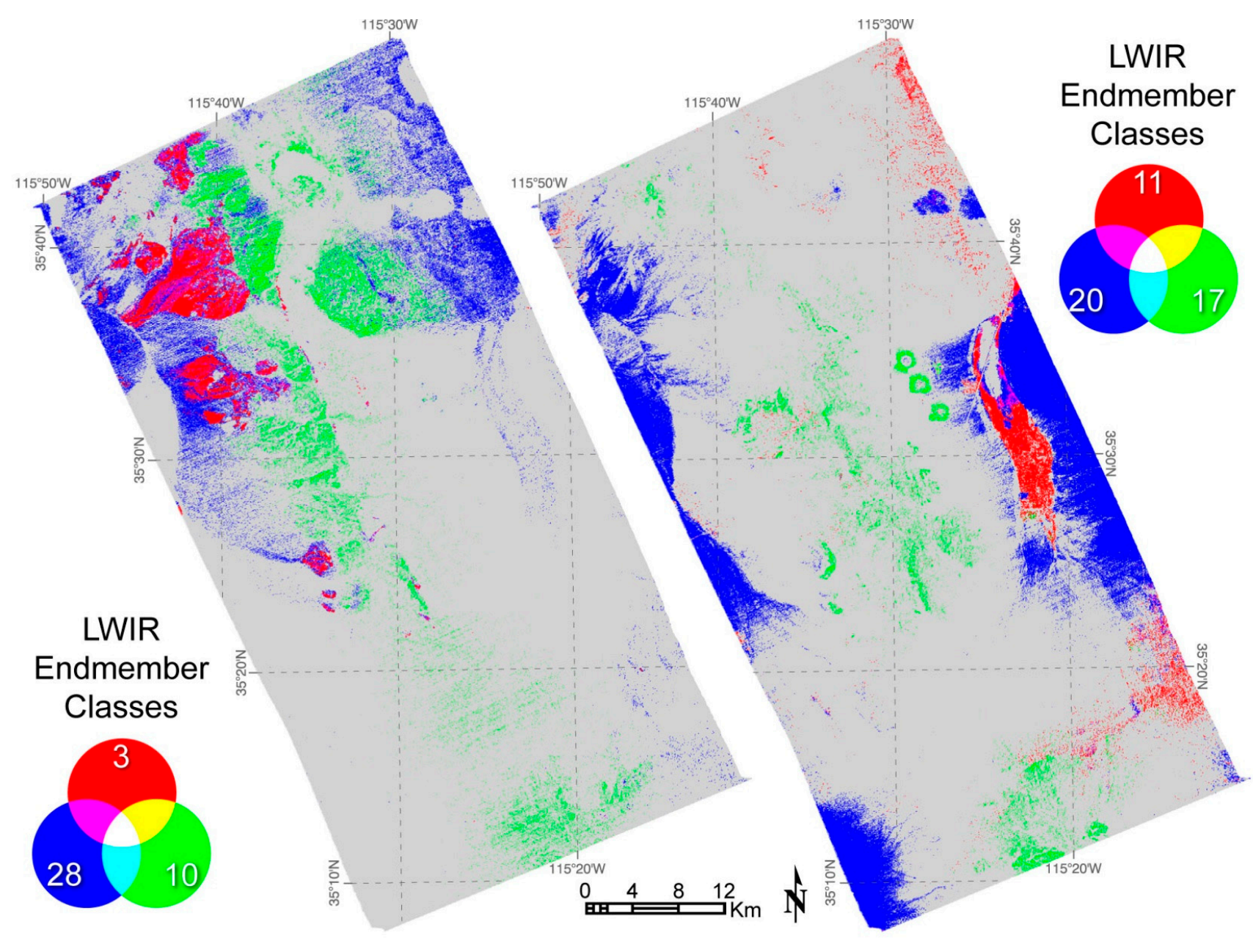

(a)

(b)

Figure 10. False color composite images of selected longwave infrared (LWIR) endmember classes: (a) 3/10/28 in red/green/blue; (b) 11/17/20 in red/green/blue. Pixels with approximate abundance values less than $40 \%$ for the selected endmembers are masked in gray. 
The characteristics of Class 28 are more complex. It is modeled in some sedimentary units, particularly the Paleozoic sedimentary (carbonate) units in the Spring Mountains, which is consistent with the emissivity low near $11.33 \mu \mathrm{m}$ in the endmember spectrum (Figure 10a). Class 28 is also mapped in the siliciclastic units, similar to Class 3, but appears to have low abundance in pixels where Class 3 has high abundance. Additionally, this class is mapped extensively in the alluvial deposits from these rock units.

The endmember spectra of several classes have decreasing emissivity from the $8.18 \mu \mathrm{m}$ band to an emissivity minimum at $9-10 \mu \mathrm{m}$, which is consistent with a variety of materials, and are commonly mapped in similar areas (e.g., Classes 13, 17 and 22-25). Their modeled distribution is sparsely scattered throughout much of the area but concentrated in the Early Proterozoic metamorphic and intrusive units, the small Jurassic intrusion in the southwestern Clark Mountains, and specific, relatively small locations within the siliciclastic units (Figure 10b). Many of these classes are also modeled in the solar panel arrays and in the southern portion of the Ivanpah Playa. Another group of LWIR classes are mapped at high abundances in the southern part of the Ivanpah Playa, as well as scattered in the central and eastern New York Mountains and Spring Mountains at moderate abundances, and sparsely scattered elsewhere (e.g., Classes 11, 12, 18, 21 and 26) (Figure 10b). Their endmember spectra share a broadly similar shape with increasing emissivity from the $8.18 \mu \mathrm{m}$ band to the $9.06 \mu \mathrm{m}$ band, then decreased emissivity to the $10.1 \mu \mathrm{m}$ band. The central portion of Ivanpah Playa is modeled with high abundances of LWIR Class 9, also mapped at slightly lesser abundances in the Mesquite Dry Lake and small western playa deposits, and sparsely scattered in the Spring Mountains.

The Class 20 endmember spectrum has low emissivity in the $8-9 \mu \mathrm{m}$ bands, which may suggest a silica-rich composition. The class is modeled at significant abundances in the extensive alluvial fan and eolian sand deposits in the regions, and also to one rock unit, the Cretaceous and/or Tertiary rhyolite intrusion in the Spring Mountains (Figure 10b).

The LWIR Classes 2, 4, 7, 14-16 and 27 (Figure 9b) have a very limited distribution; they are modeled at their highest abundances in areas that include manmade surfaces and structures. The endmember spectra have a maximum emissivity in the $\sim 9-10 \mu \mathrm{m}$ region corresponding to the prominent ozone feature, suggesting a substantial contribution from atmospheric downwelling radiance, consistent with the emissivity spectra of highly reflective materials such as metals that have not been corrected for this component, as is the case for the ISAC method applied here.

\subsection{Integration and Classification}

\subsubsection{Image Co-Registration Assessment}

Some amount of error is expected when registering one data set to another with a large difference in pixel size. Our co-registration error analysis found a mean offset of $\sim 44 \mathrm{~m}$ (standard deviation of $23 \mathrm{~m}$ ) for the test points between the AVIRIS VNIR-SWIR and MASTER LWIR registered imagery. No spatial correlation was observed. This mean offset error represents $\sim 1.3$ pixels of the $34.4 \mathrm{~m} /$ pixel LWIR data. For the integrated classification map, which was produced by data that were resampled to the smallest pixel size, this translates to a mean offset error of $\sim 2.8$ pixels (standard deviation of $\sim 1.5$ pixels). Registration error must be considered when analyzing the integrated map; classes present only along the edges of features or less than 5 or 6 pixels wide should be investigated closely to determine if mis-registration has combined VNIR-SWIR and LWIR information incorrectly.

\subsubsection{Full-Range Classification}

The ISODATA cluster analysis of the joined VNIR-SWIR-LWIR endmember apparent abundance values grouped the data into 54 classes and produced the integrated classification map shown in Figure 11. The distributions of the majority of classes correspond to specific rock types and their alluvial deposits, or other surficial deposits and materials. For example, Classes 6, 8, 12 and 17 correspond to siliciclastic units, Classes 30 and 41 are mapped to metamorphic and intrusive units, 
Classes 4, 16, 18, 19, 24, 38, 45 and 52 match carbonate units, and Class 21 represents concentrated areas of green vegetation. Only a few classes are sparsely scattered over multiple rock types and surfaces (e.g., Classes 39, 43 and 49). There are no classes that exclusively correspond to surfaces composed of manmade materials or REE-bearing phases. In areas where these surfaces are present we commonly observe a scattered variety of classes that predominantly correspond to larger surface compositions. There is typically no recognizable spatial pattern in the pixel distribution of these classes, except for larger features such as the road surface of Interstate 15, which is mapped mostly by classes with a high abundance in the SWIR calcite or dolomite endmembers, though some pixels are scattered along its extent from other classes.

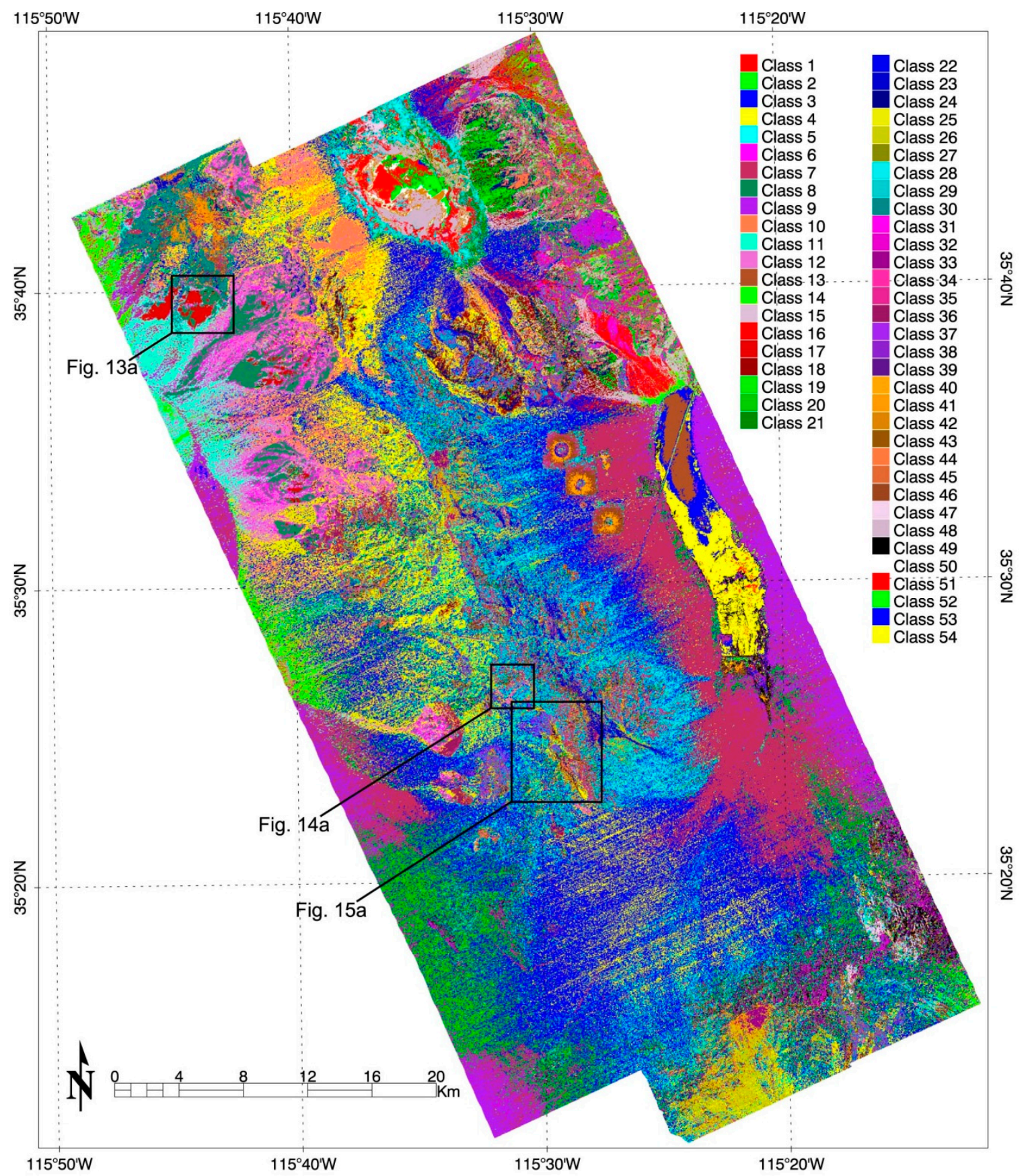

Figure 11. Classification map produced from integration of the visible to near infrared (VNIR), shortwave infrared (SWIR), and longwave infrared (LWIR) image endmembers. The map subsets shown in subsequent figures re outlined in black. 
In Figure 12 we plot examples of the mean endmember abundance values that describe and differentiate the classes. Most classes appear to be dictated by the LWIR abundances (e.g., Classes 4, 14, 32, 39, 43 and 49), but several are characterized by high abundances of VNIR and/or SWIR endmembers (e.g., Classes 17, 19, 21, 23, 38, 42 and 47). In some cases, it is apparent that surfaces with similar endmember abundances in one or two wavelength ranges exhibit abundance differences in another. A few examples can be observed in Figure 12. Classes 7 and 9 share similar VNIR and SWIR mean endmember abundance values, but their LWIR abundance values differ. The VNIR and LWIR mean abundance values are almost the same for Classes 19 and 38, but they are different in the SWIR. For Classes 39 and 47 distinct variations occur in both the VNIR and SWIR mean endmember abundances, whereas their LWIR mean endmember abundances are very similar.

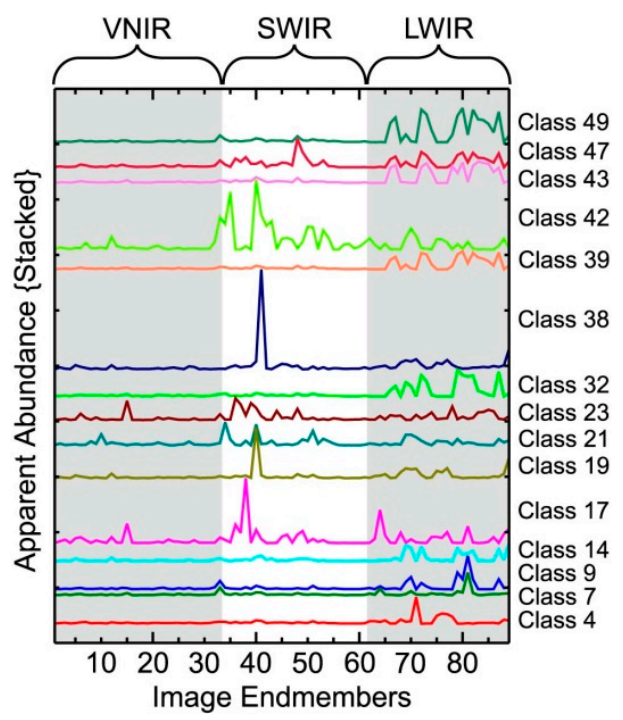

Figure 12. Mean endmember apparent abundance values for selected classes produced by integration of the visible to near infrared (VNIR), shortwave infrared (SWIR), and longwave infrared (LWIR) image endmembers.

\section{Discussion}

\subsection{Integrated Unit Demonstrations}

One goal of this study was to integrate VNIR, SWIR, and LWIR data in a way that preserved the strengths of each wavelength range. We find that the final integrated full-range classification map does incorporate many of the attributes of the individual ranges. Several examples demonstrating the influence of the VNIR, SWIR, and LWIR compositional information in the integration are described below.

\subsubsection{Siliciclastic Unit Demonstration}

Integrated Classes 8 and 17 are mapped in the Late Proterozoic to Cambrian siliciclastic rock unit (Figures 2 and 11) and can be clearly linked to particular SWIR and LWIR contributions (Figure 13). As shown in the mean abundance graph (Figure 13b), the endmember with the highest mean abundance for ROI A within Class 17 is SWIR 5, a class representing the minerals muscovite/illite, whereas the LWIR 3 endmember, which is the most silica-rich, has the highest mean abundance for ROI B within Class 8. The SWIR 5 and LWIR 3 abundance distribution images (Figure 13c) illustrate the spatial variation of the abundance values, which correspond strongly with the integrated Classes 17 and 8 distributions, respectively. The mean abundance graph shows that other endmembers are also present but at much lower abundances. 
The mean spectra of ROIs A and B manifest the character indicated by their integrated classes. The shape of the ROI A and B spectra are very similar in the VNIR, indicating the presence of iron oxide (goethite), but the ROI A spectrum exhibits more distinct muscovite/illite features in the SWIR (Figure 13d). The SWIR features of the ROI B spectrum are more subdued, which could be consistent with a greater proportion of quartz or silica, which has a broad and shallow $\sim 2.2 \mu \mathrm{m}$ minimum. The LWIR mean spectrum of ROI B has a lower emissivity in the $8.18,8.62$, and $9.06 \mu \mathrm{m}$ bands than the ROI A mean spectrum, indicating a more silica-rich composition (Figure 13e).

(a)

(c)

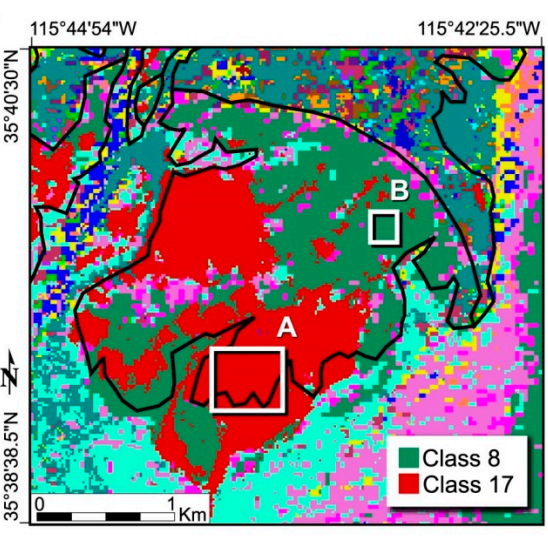

(b)
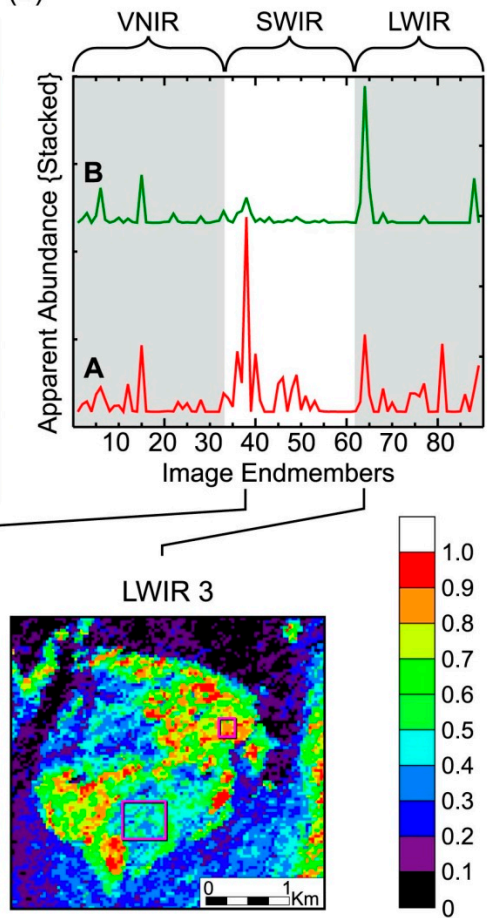

(d)

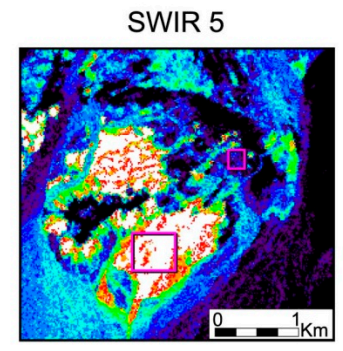

LWIR 3

(e)
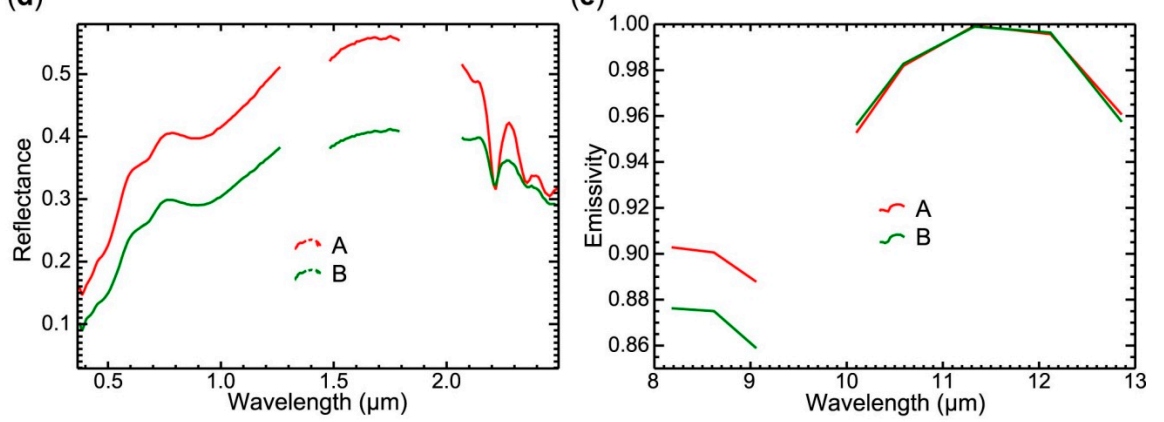

Figure 13. Examination of individual wavelength range results incorporated in the full-range characterization of a siliciclastic rock unit: (a) subset of the integrated classification map with outlines of general surface units and regions of interest corresponding to subsequent plots; (b) graph of mean endmember abundance values for selected regions of interest, offset for clarity; (c) abundance distribution images for notable endmembers; (d) mean visible to near infrared (VNIR) and shortwave infrared (SWIR) spectra of selected regions of interest; (e) mean longwave infrared (LWIR) spectra of selected regions of interest.

The integrated full-range classification map provides details about this siliciclastic rock unit beyond what could be learned from each range alone; it indicates that some areas are more silica-rich than others, and that the less silica-rich areas are instead enriched in the phyllosilicate minerals muscovite and/or illite. This is consistent with the known variety of quartzite, sandstone, siltstone, 
and shale layers generally found in this siliciclastic unit [29,31,32]. Inspection of visible imagery and topography suggests that the more silica-rich material corresponds to a layer predominantly on topographic highs and its alluvium on hillslopes and in valleys. The muscovite/illite material appears to correspond to a topographically lower and lighter toned layer.

\subsubsection{Quartz-rich Sandstone Unit Demonstration}

The influence of the MASTER LWIR spectral analysis results is apparent in the mapping of the Jurassic quartz-rich sandstone unit with integrated Classes 10 and 12 (Figures 2,11 and 14). The graph in Figure 14b of mean endmember abundances for ROIs A-D from the sandstone unit shows that the LWIR 3 and 28 endmembers have the highest abundances, greater than any in the VNIR and SWIR. The abundance images in Figure 14c illustrate how closely the elevated abundances of the LWIR 3 and 28 endmembers correspond to the unit location.

(a)

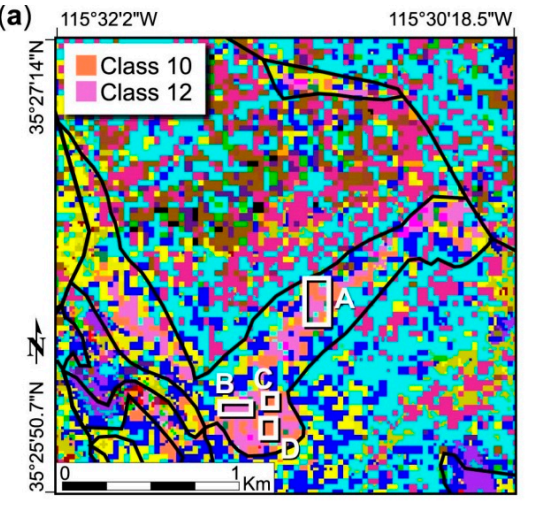

(c)

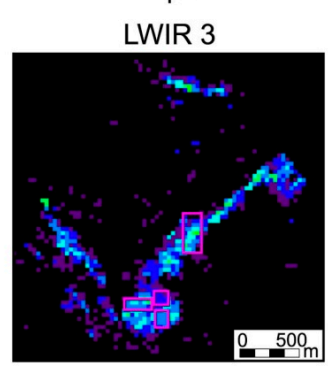

(d)

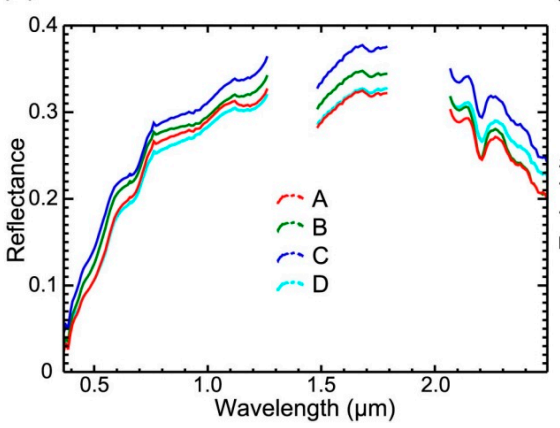

(b)

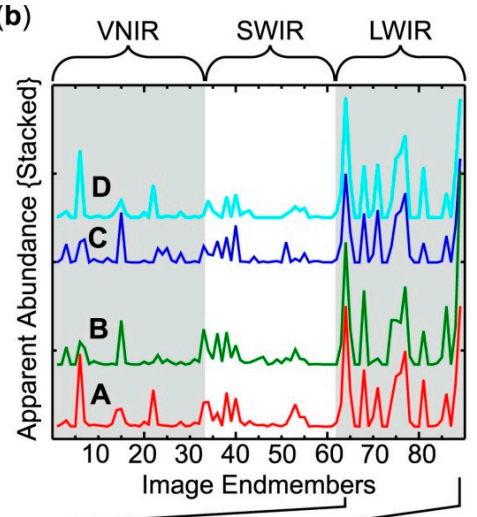
Image Endmembers

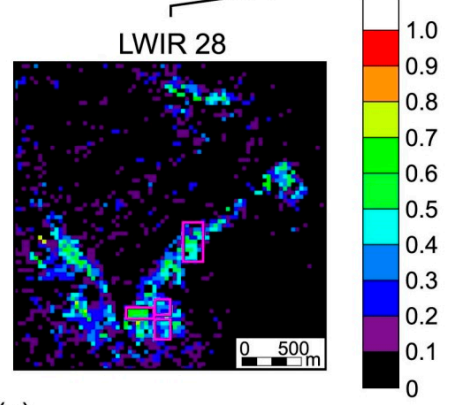

(e)

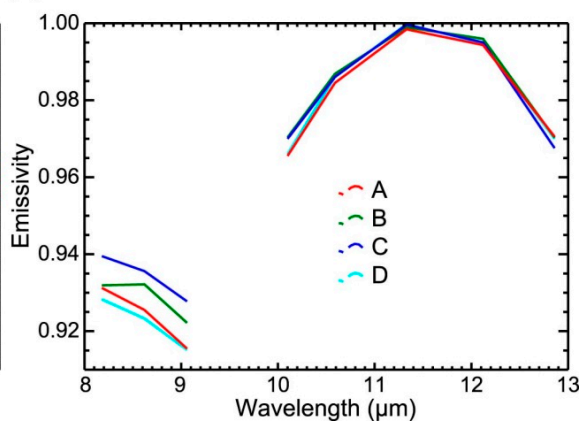

Figure 14. Examination of individual wavelength range results incorporated in the full-range characterization of a quartz-rich sandstone unit: (a) subset of the integrated classification map with outlines of general surface units and regions of interest corresponding to subsequent plots; (b) graph of mean endmember abundance values for selected regions of interest, offset for clarity; (c) abundance distribution images for notable endmembers; (d) mean visible to near infrared (VNIR) and shortwave infrared (SWIR) spectra of selected regions of interest; (e) mean longwave infrared (LWIR) spectra of selected regions of interest. 
We selected ROI B to include only Class 12 pixels and ROIs C and D to include only Class 10 pixels. A comparison of the mean endmember abundances of these ROIs suggest that the two classes share high abundances in most of the same LWIR endmembers, but the abundance of the LWIR 28 endmember is notably higher in the Class 12 ROI B. This comparison holds for the mean abundance values when considering all the Class 10 and 12 pixels in the integrated map. The mean abundances of ROIs C and D, both within Class 10, indicate that the high LWIR endmember abundance values are more definitive for these classes than the lower VNIR or SWIR endmember abundances, which vary.

The VNIR-SWIR spectra of ROIs A-D are similar, exhibiting slight iron oxide influence and vegetation features and shallow muscovite/illite features (Figure 14d). The LWIR mean spectra of the ROIs share the same overall shape with low emissivity in the 8.18,8.62, and $9.06 \mu \mathrm{m}$ bands indicating the silica-rich composition (Figure 14e). The ROI B mean spectrum differs slightly from the others by having a higher emissivity in the $8.62 \mu \mathrm{m}$ band relative to the $8.18 \mu \mathrm{m}$ band.

With VNIR and SWIR data alone the quartz-rich sandstone unit is not distinctive. Its silica-rich composition is distinguishable in the LWIR data and remains clearly defined in the integrated full-range classification map.

\subsubsection{Carbonate Unit Demonstration}

Detailed information about the Paleozoic carbonate unit (Figure 2) is incorporated into the integrated classification map from both the SWIR and LWIR analysis results (Figure 11). In the area shown in Figure 15, the unit is mapped with a mixture of several integrated classes. Areas of greater compositional variation are distinguished by different class combinations, such as Classes 29, 37, 38 and 52 (ROI A), Classes 18, 24, and 26 (ROI B), and Classes 19, 24 and 44 (ROI C). These class combinations share similarly low VNIR and SWIR endmember abundances with the exception of SWIR Classes 7 (dolomite) and 8 (calcite), which have high abundances in the ROIs B and C and ROI A groupings, respectively (Figure 15b). Slight differences in the LWIR endmember abundances may contribute to the differentiation of these classes, along with the magnitude of the SWIR 7 or 8 abundance. The abundance images in Figure 15c illustrate how the distribution of the SWIR 7 and 8 abundances correspond to the integrated class groupings.

The classes high in SWIR carbonate abundance do not cover the full extent of the carbonate unit as defined by previous geologic maps (Figure 2). From the mean endmember abundances of ROI D located within one of these uncovered areas (Figure 15b), we observe that the presence of carbonate is still suggested by the elevated abundance of LWIR endmember 10, which may exhibit carbonate spectral features. The distribution of LWIR 10 shows a more consistent elevated abundance throughout the carbonate unit (Figure 15c).

The mean VNIR-SWIR spectra of ROIs A, B and C shown in Figure 15d are very similar except for the minimum at $2.336 \mu \mathrm{m}$ for ROI A (calcite) and $2.316 \mu \mathrm{m}$ for ROIs B and C (dolomite), consistent with their mean endmember abundances. The ROI D VNIR-SWIR mean spectrum has a very shallow $2.3 \mu \mathrm{m}$ feature, reflecting its more indistinct character in the SWIR. The LWIR mean spectra for ROIs A-D have low spectral contrast with a minimum emissivity of 0.97 or higher, but they do differ in some details (Figure 15e). The ROIs B and D spectra exhibit an emissivity minimum in the $11.33 \mu \mathrm{m}$ band that is consistent with their high abundance of the LWIR 10 endmember and carbonate. ROI C has only a slightly elevated LWIR 10 abundance and its spectrum has neither an emissivity minimum or maximum at this position. No LWIR endmembers have high abundance in ROI A, and no carbonate feature is apparent in its LWIR spectrum.

The incorporation of the SWIR calcite and dolomite endmembers and the LWIR carbonate-bearing endmember reveals compositional variation that likely corresponds to layers within this general rock unit that differ in characteristics such as the predominant carbonate mineral and content of chert, sand, or clay minerals. 
(a)

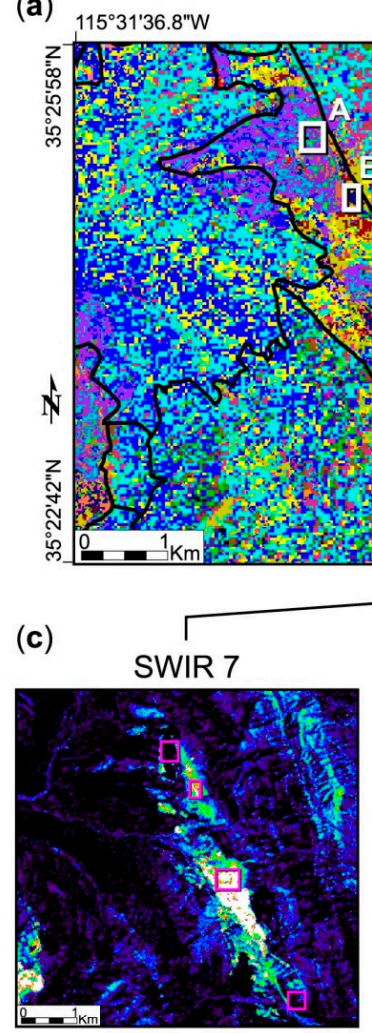

(d)

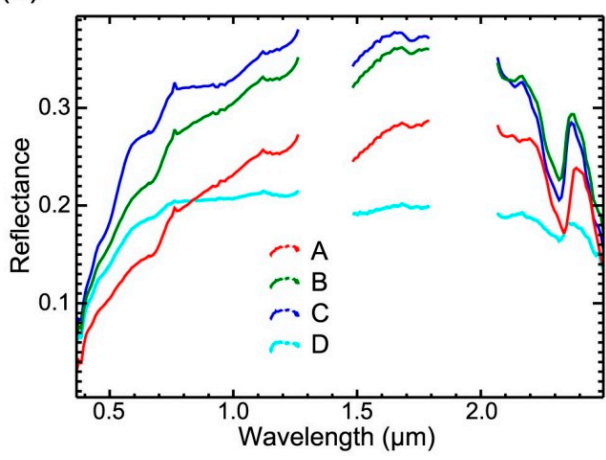

(b)
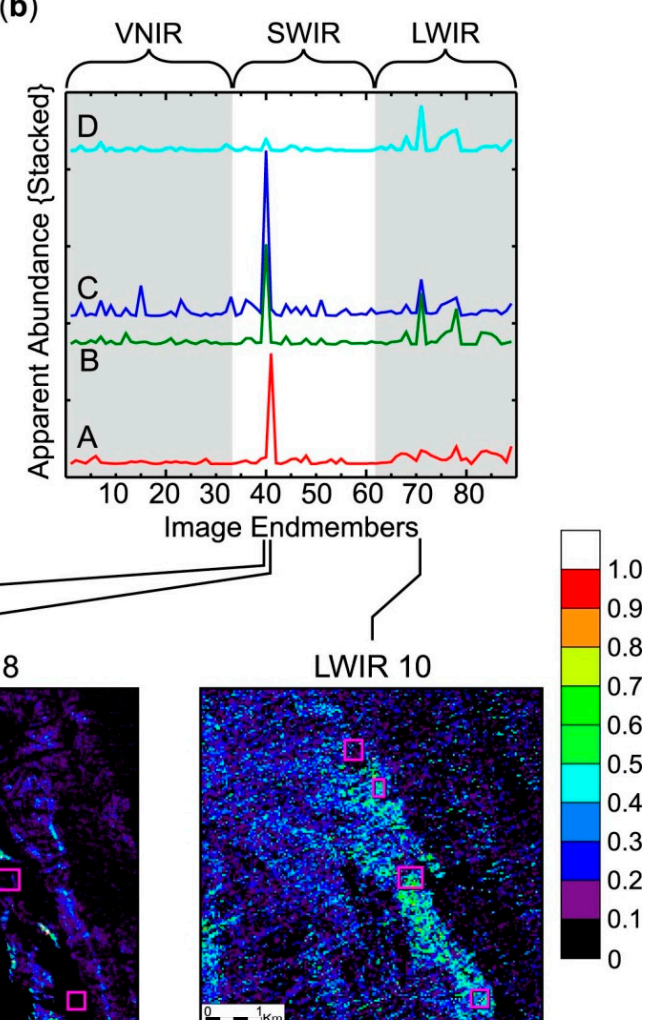

(e)

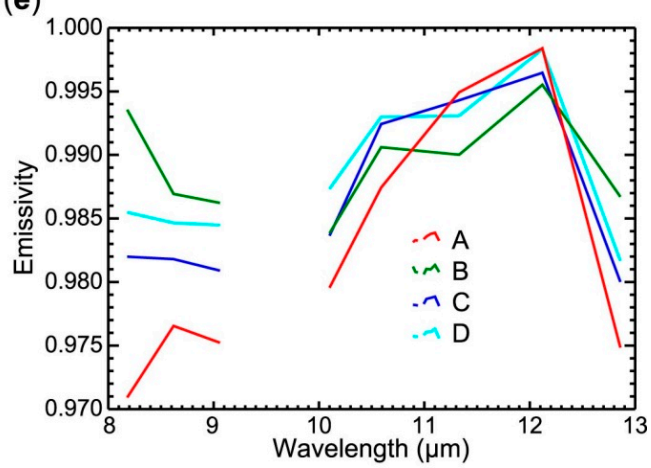

Figure 15. Examination of individual wavelength range results incorporated in the full-range characterization of a carbonate unit: (a) subset of the integrated classification map with outlines of general surface units and regions of interest corresponding to subsequent plots; (b) graph of mean endmember abundance values for selected regions of interest, offset for clarity; (c) abundance distribution images for notable endmembers; (d) mean visible to near infrared (VNIR) and shortwave infrared (SWIR) spectra of selected regions of interest; (e) mean longwave infrared (LWIR) spectra of selected regions of interest.

\subsection{Mako LWIR Examination}

A Mako emissivity mosaic is shown in Figure 16 with the bands at 8.59, 11.32, and $12.10 \mu \mathrm{m}$ displayed in red, green, and blue, respectively. We selected these bands for display rather than the commonly used "standard" 10/9/8 $\mu$ m combination to most effectively highlight the spectral variation particular to this scene. Large areas appearing red and cyan in this band combination suggest that two types of terrain make up the majority of the scene (principally carbonate versus silicate, discussed below). Spots of water stand out as bright green. The interstate is a distinct magenta whereas the other small roads are predominantly shades of blue. Numerous building roofs and other manmade 
objects, including vehicles, appear as discrete features in black, red, magenta, or shades of green. Areas of vegetation are displayed in yellow-green clusters or small spots scattered throughout the terrain. The color corresponding to bare soil varies, particularly in the sediment piles and mine pit.

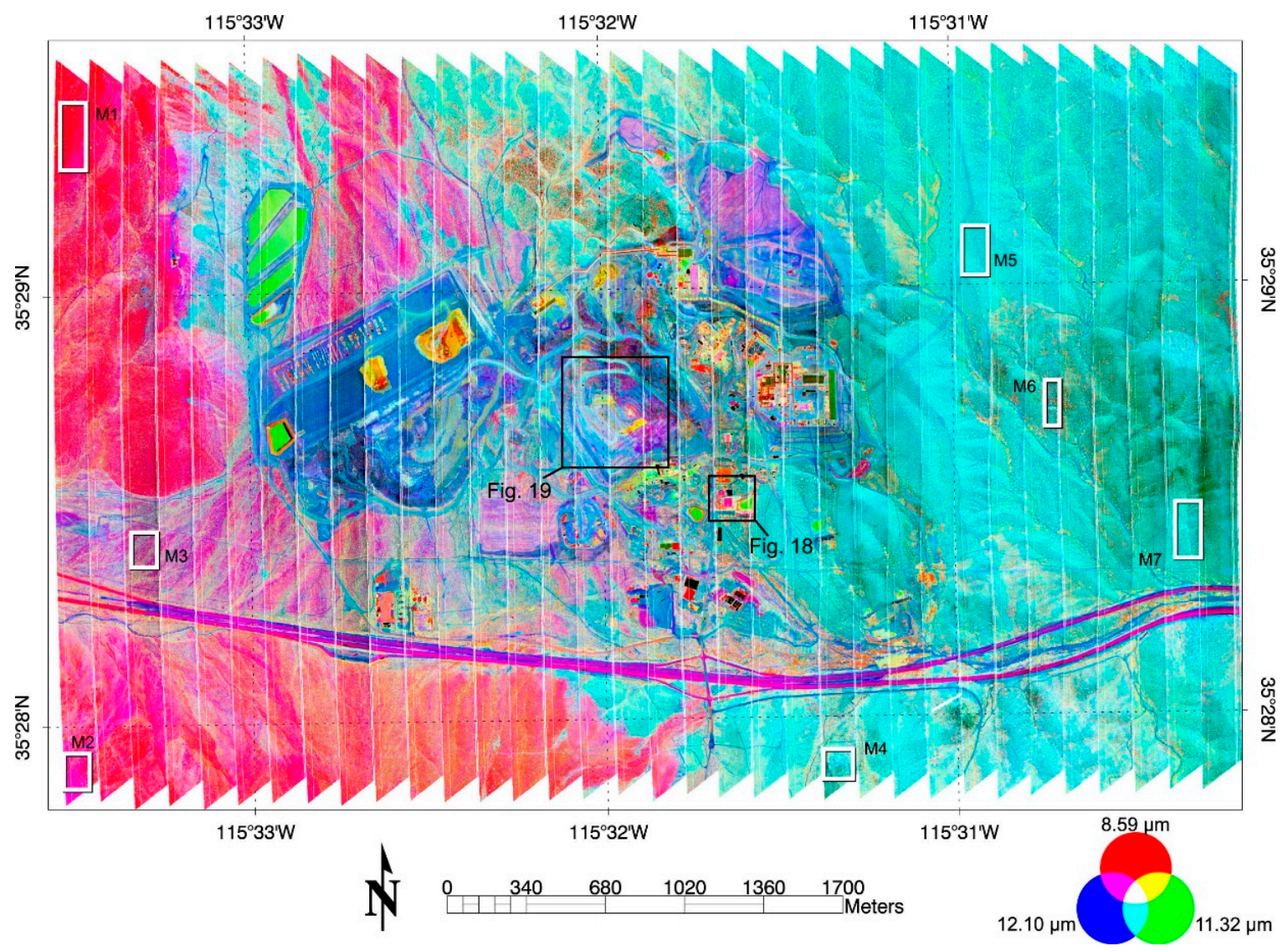

Figure 16. False color composite mosaic of the Mako emissivity data with bands 8.59/11.32/12.10 $\mu \mathrm{m}$ displayed in red/green/blue. The white boxes outline regions of interest discussed in the text and Figure 17. The black boxes outline the data subsets shown in Figures 18 and 19.

The average Mako emissivity spectra from ROIs M1 to M7 (Figure 16) provide examples of the terrain surrounding the mining facility and are plotted in Figure 17a. M1, M2 and M3 are from the western terrain (red in Figure 16) and reveal that this is a carbonate-bearing composition. Specifically, the position of the $\sim 11.2-11.3 \mu \mathrm{m}$ feature indicates dolomite in the M1 spectrum and calcite in the M2 spectrum. These spectra appear very similar at the spectral resolution of the MASTER LWIR bands (Figure 17b), and the difference in the $\sim 11.2-11.3 \mu \mathrm{m}$ feature cannot be discerned. The ROIs M4, M5, M6 and M7 are from the eastern terrain (cyan in Figure 16), and their spectra suggest compositions that lack carbonate and have varying proportions of silicate materials consistent with the metamorphic and intrusive igneous rocks indicated from geologic maps (refer to Figure 2). At MASTER LWIR spectral resolution (Figure 17b) these average spectra exhibit slight differences, but further investigation shows that their standard deviations overlap in all bands except between ROIs M4 and M5, suggesting that confident differentiation between these compositions may be difficult at this spectral resolution. 


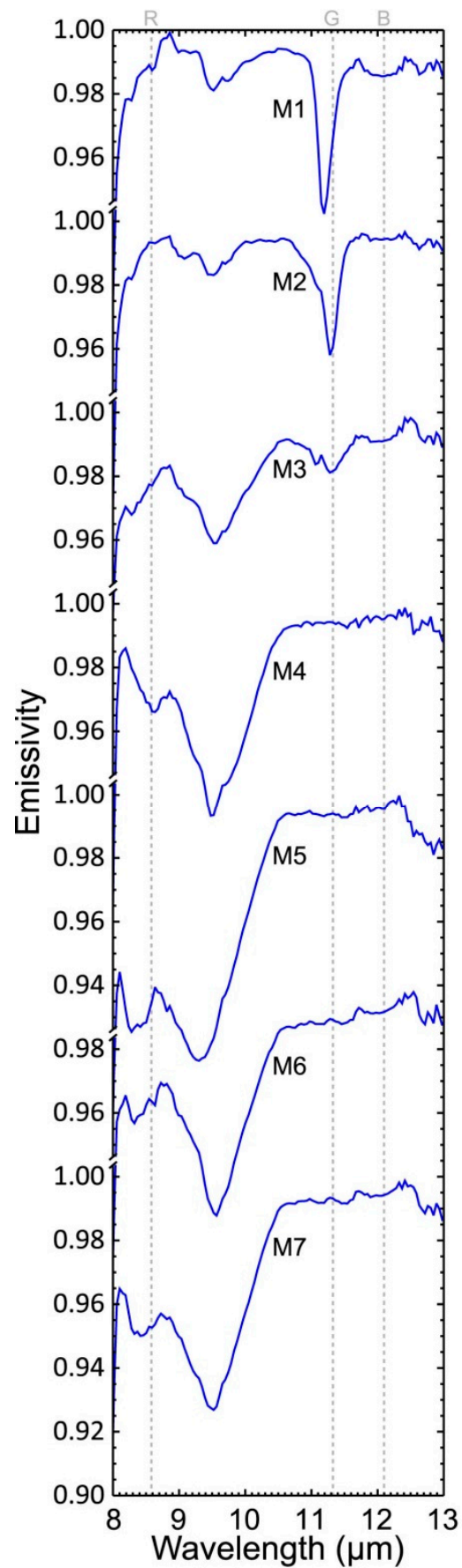

(a)

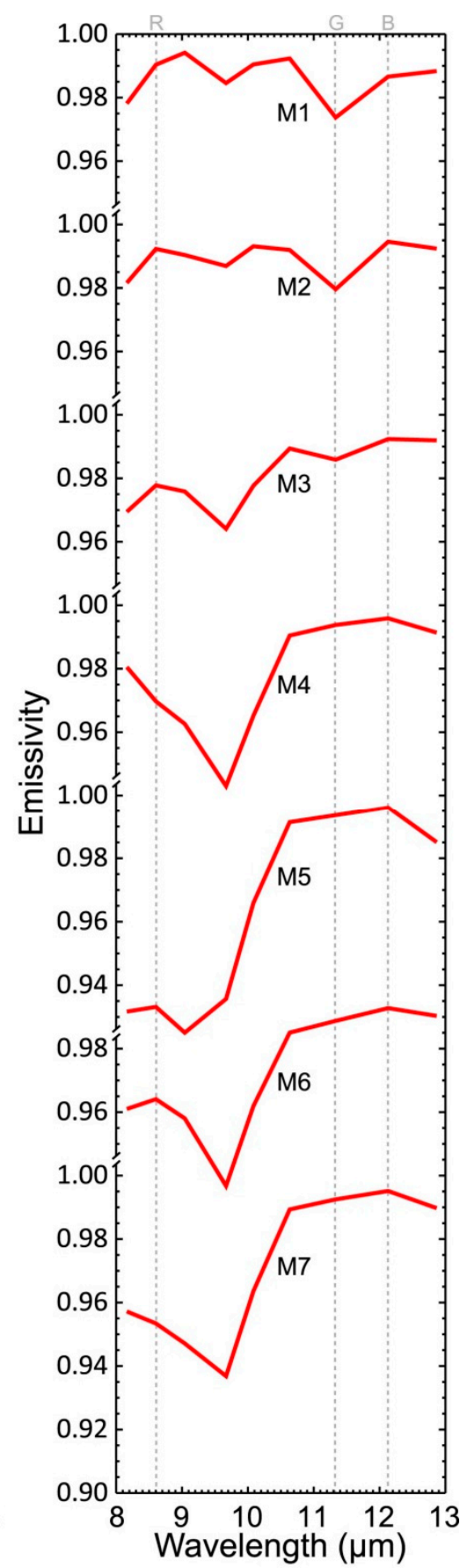

(b)

Figure 17. Mean emissivity spectra of regions of interest (ROI) M1-M7 from the Mako data at: (a) Mako native spectral resolution; (b) convolved to the spectral response functions of the MODIS/ASTER Airborne Simulator (MASTER) longwave infrared bands. See Figure 16 for ROI locations; gray dashed lines indicate band positions displayed as red (R), green (G), and blue (B) in Figure 16.

Figure 18 shows a subset of the Mako image with examples of building roofs (ROIs A1, A2), vegetation (ROI A3), and natural terrain (ROI A4), along with their Mako spectra at native spectral resolution (Figure 18b) and convolved to MASTER LWIR bandpasses (Figure 18c). The Mako mean spectra of ROIs A1 and A2 both represent roofs but are clearly different from each other as well as the surrounding materials. Roof A1 appears to be a highly reflective surface (e.g., metallic) with an emissivity spectrum affected by insufficient atmospheric compensation and temperature-emissivity 
separation. The features in the roof A2 spectrum are consistent with a synthetic plastic or rubber material with contribution from a carbonate component. The average Mako emissivity spectrum of ROI A3, a nearby cluster of trees, has low spectral contrast, which is common for remote measurements of vegetation [67]. The trees' emissivity features are obscured by small emission minima that actually appear to be inverted reflected downwelling radiance features introduced by the atmospheric compensation procedure, which slightly overcompensated in the adjustment for the downwelling radiance reflected into the sensor by this high emissivity surface. The ROI A4 mean spectrum represents an area of natural terrain within the mining complex and is very similar to the mean spectrum from the M6 ROI further to the east (Figures 16 and 17a). The spectra of these materials are sufficiently different from one another to be discriminated at the MASTER spectral resolution also (Figure 18c).

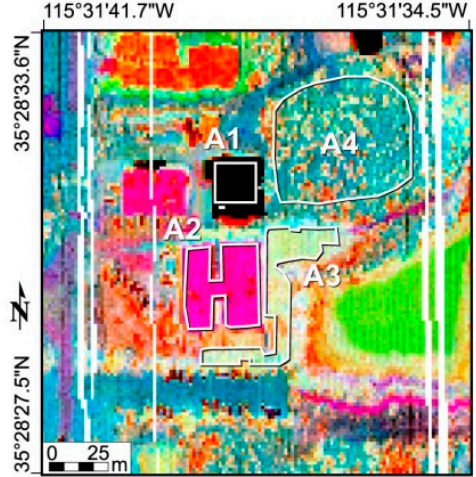

(a)

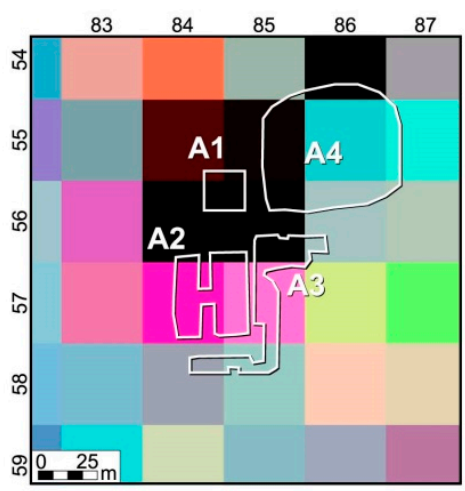

(d)

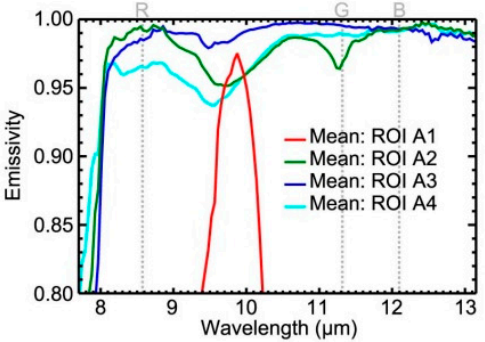

(b)
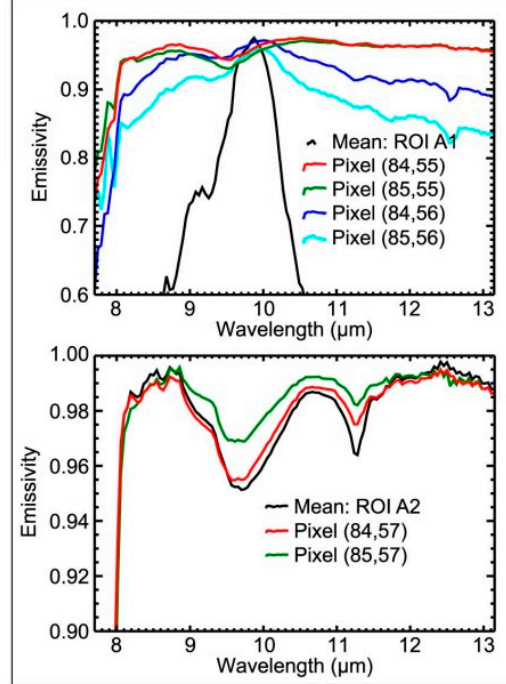

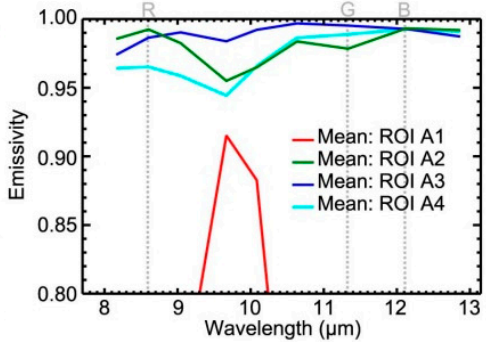

(c)
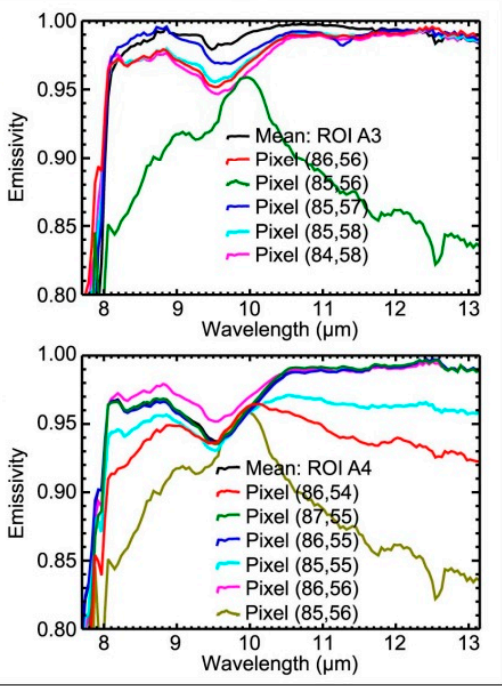

(e)

Figure 18. Detailed examination of a subset of the Mako emissivity data: (a) outlines of selected regions of interest (ROIs) on the false color composite image with bands 8.59/11.32/12.10 $\mu \mathrm{m}$ displayed as red/green/blue; (b) mean emissivity spectra of the ROIs; (c) mean emissivity spectra of the ROIs convolved to the spectral response functions of the MODIS/ASTER Airborne Simulator (MASTER) longwave infrared bands; (d) ROI outlines on Mako data resampled to the pixel size of our MASTER data set; (e) mean emissivity spectrum of each ROI plotted with the spectra of the new resampled pixels to which it contributes.

These ROIs occupy portions of multiple pixels after aggregation to model the coarser spatial resolution of the MASTER LWIR data set (Figure 18d). Spectra from each of the new pixels containing part of the ROI are plotted with the mean spectrum of the ROI from the original spatial resolution in Figure 18e. The roof ROI A1 is predominantly covered by the new pixels $(84,56)$ and $(85,56)$; the spectra of these new pixels have a drop off in emissivity to either side of the $\sim 9.9 \mu \mathrm{m}$ maximum that is not as extreme as in the ROI A1 spectrum but still reveals the influence of that reflective material. The new pixels $(84,55)$ and $(85,55)$ received only a small contribution from the roof, and its influence in 
not apparent in their spectra. Almost all of the roof ROI A2 is within the two new pixels $(84,57)$ and $(85,57)$. Their spectra are noticeably similar to the mean spectrum of the roof, indicating its presence. Several of the new pixels contain portions of ROI A3, but none of the new spectra closely resemble the ROI A3 spectrum. The low spectral contrast of the vegetation spectra may influence the aggregated spectrum by reducing its spectral contrast more than changing its shape, making the presence of the vegetation difficult to observe in the larger mixed pixels. As ROI A4 completely encompasses one of the new pixels, that pixel's spectrum exhibits little difference from the mean ROI A4 spectrum. The other new spectra appear to be mostly a mixture between the ROI spectrum and reflective building roof. Spectra from pixels $(86,55),(87,55),(86,56)$, and even $(85,55)$ may be similar enough to allow the natural terrain to still be detectable at the larger pixel size, but the distinguishing features are lost in the other pixels.

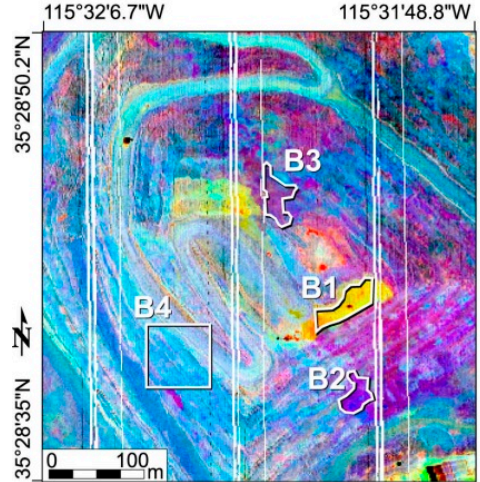

(a)

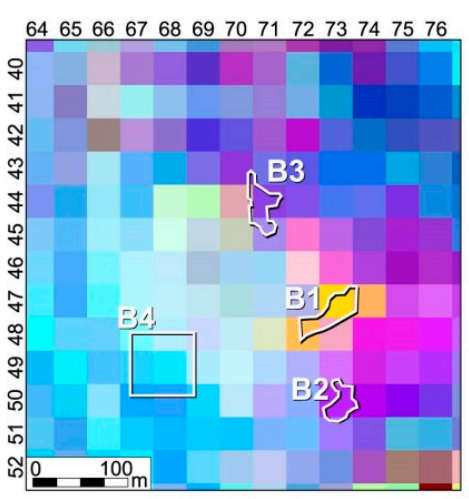

(d)

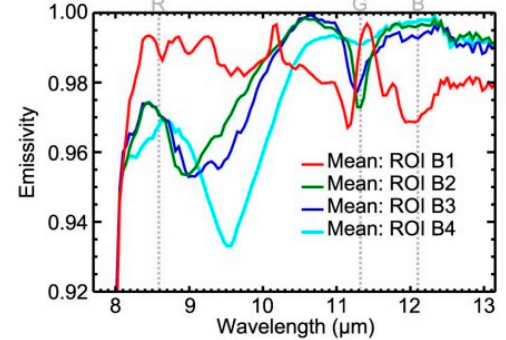

(b)
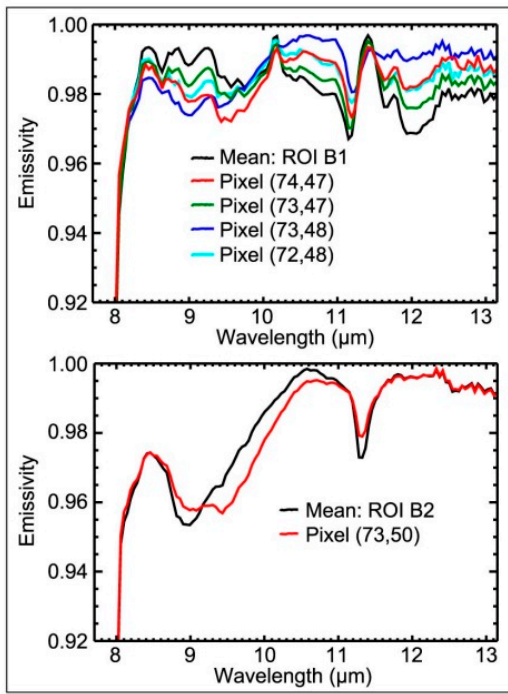

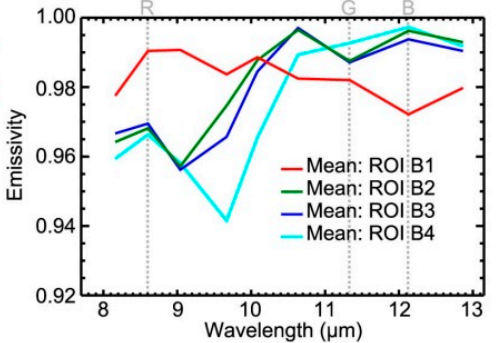

(c)
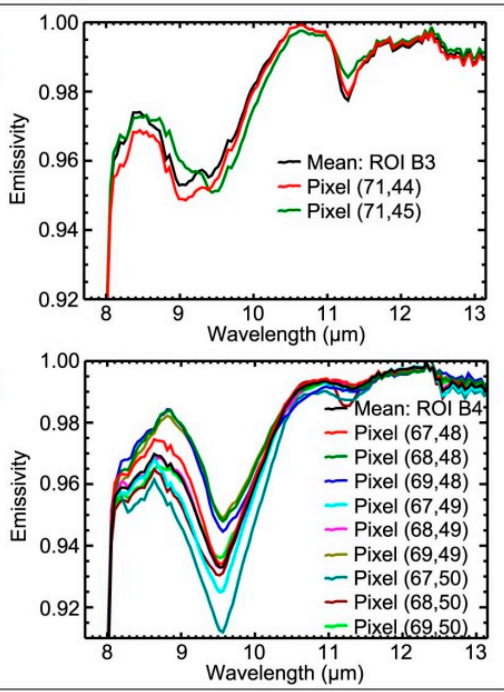

(e)

Figure 19. Detailed examination of a subset of the Mako emissivity data: (a) outlines of selected regions of interest (ROIs) on the false color composite image with bands 8.59/11.32/12.10 $\mu \mathrm{m}$ displayed as red/green/blue; (b) mean emissivity spectra of the ROIs; (c) mean emissivity spectra of the ROIs convolved to the spectral response functions of the MODIS/ASTER Airborne Simulator (MASTER) longwave infrared bands; (d) ROI outlines on Mako data resampled to the pixel size of our MASTER data set; (e) mean emissivity spectrum of each ROI plotted with the spectra of the new resampled pixels to which it contributes.

An example of the small scale exposures of unique compositions is given in Figure 19, which outlines selected ROIs in the REE mine pit. The average Mako emissivity spectra of these ROIs are plotted in Figure 19b. The spectrum of ROI B1 suggests a mixture of a fine grained carbonate, indicated by the inversion of the $\sim 11.3 \mu \mathrm{m}$ feature, and other phases yet to be determined from the existing spectral libraries. The spectra of ROIs B2 and B3 represent mixtures containing coarse grained carbonate, likely calcite and dolomite, respectively, based on the different positions of their 
$\sim 11.2-11.3 \mu \mathrm{m}$ features. The spectrum of ROI B4 has a very shallow $\sim 11.3 \mu \mathrm{m}$ feature that indicates it contains much less carbonate than the other ROIs; it is generally similar to the non-carbonate compositions of the surrounding terrain (e.g., ROI M6, Figures 16 and 17). At the decreased spectral resolution of the MASTER LWIR bandpasses (Figure 19c), ROIs B1 and B4 may still be distinguished from each other and from ROIs B2 and B3, but ROIs B2 and B3 may be too similar to be reliably differentiated from one another.

The outlines of these ROIs superposed on the larger pixels of the Mako data resampled to mimic our MASTER data are shown in Figure 19d. Portions of ROI B1 are contained within four of the new larger pixels. As shown in Figure 19e, the spectra of new pixels $(73,47)$ and $(72,48)$ are similar to the mean spectrum of ROI B1 and could allow for the detection of the B1 material. The spectrum of new pixel $(74,47)$ may be similar enough as well, but the other new pixel $(73,48)$ has some different features and this mixing may make the B1 material more difficult to identify. Almost all of the ROI $\mathrm{B} 2$ is contained within one of the new pixels. The influence of the materials from the rest of the pixel results in a spectrum that differs from the mean ROI B2 spectrum, though the $\sim 11.3 \mu \mathrm{m}$ feature is still clear. The majority of ROI B3 is contained within two pixels. The spectrum of pixel $(71,44)$ is very similar to the mean ROI B3 spectrum and could indicate the presence of that composition, but in the spectrum of pixel $(71,45)$ mixing complicates the detection of that exact composition beyond the presence of dolomite from the $\sim 11.3 \mu \mathrm{m}$ feature. The more extensive ROI B4 contributed to several of the new pixels, though contribution to some was small, such as pixels $(67,50)$ and $(68,50)$, and their spectra exhibit noticeable differences from the mean ROI B4 spectrum. Some spectra are very similar to the ROI B4 spectrum (e.g., pixel $(68,49))$ and preserve the opportunity for the B4 material to be detected. Spectra from the majority of the new pixels differ from the ROI B4 mean spectrum slightly but may still be similar enough to indicate its presence.

\subsection{Spatially Limited and/or Uncommon Compositions}

There are some materials that are distinguished in one or more of the independent spectral analyses but are not discernable in the final integrated full-range classification map. These materials are primarily small, covering only a few $15 \mathrm{~m}$ pixels, and/or are uncommon within the study region, and include materials such as building roofs, exposures of REE-bearing phases, and some spots of vegetation. The larger pixel size of the MASTER LWIR data may limit the preservation of small features after integration, especially combined with any co-registration error. Our comparison exercise with Mako emissivity data convolved to the MASTER LWIR spectral response functions shows that many small features not distinguished in the MASTER LWIR data are apparent at a smaller pixel size (Figures 18c and 19c). The exercise also illustrates that even with the larger MASTER LWIR pixel size, the influence of many spatially limited features are discernable with Mako's increased number of spectral bands (Figures 18e and 19e). These observations suggest that the results of our integration method may be improved for materials with limited spatial extent or occurrence with the use of data having increased spatial and/or spectral resolution.

We also considered the ISODATA parameters as a possible source of this limitation for uncommon compositions. We specified a minimum of 10 pixels per class for the ISODATA cluster analysis, which would ignore any potential integrated classes that included less than 10 pixels. Even if a minimum of 2 pixels per class is specified, there is no noticeable change in the resulting map and no new classes are added, suggesting that this parameter is not responsible for the lack of integrated classes composed of only a few pixels. Further examination of the integrated classification map reveals that pixels with uncommon compositions may be included in a class that is appropriate for most of the endmembers and the high abundance of the rare endmember is an outlier beyond the standard deviation. Setting a maximum allowable distance from the class mean in the ISODATA analysis may prevent this occurrence, leaving the pixel unclassified and indicating a unique case in need of additional consideration. If modification of the parameters does not achieve the desired result, modification of the method itself could be considered as well. Evaluation of alternative approaches to clustering and 
classification for the data integration may reveal benefits for spatially limited compositions, potentially warranting any added complexity. For example, Self-Organizing Maps [68], already widely used in the geosciences e.g., [69,70], may overcome some of the limitations of ISODATA cluster analysis [71,72] and have shown greater success in detecting unique but spatially small data clusters, e.g., [73].

\section{Conclusions}

We have extended the capabilities of spectral remote sensing for compositional mapping by taking advantage of the complementary natures of the VNIR, SWIR, and LWIR spectral ranges. Specifically, we produced a full-range spectral classification map of the region near Mountain Pass, California by integrating the results of independent VNIR, SWIR, and LWIR analyses. The image endmembers identified by the independent spectral analyses are consistent with the types of materials expected to be detectable in each wavelength range. The VNIR results highlight areas of bright playa deposits, iron oxides, green vegetation, REE-bearing materials, and manmade materials. The SWIR results show occurrences of the minerals gypsum, muscovite/illite, calcite, dolomite, and kaolinite, in addition to vegetation, REE-bearing phases, and manmade materials. The LWIR results primarily distinguish general lithology, commonly corresponding to unit boundaries. Exact identification and discrimination of some compositions is limited by the coarse spatial and spectral resolution of the MASTER LWIR data, but we discern sulfate deposits, carbonate-bearing units, silica-rich units, and the presence of reflective metallic surfaces.

The full-range classification map created from the integration of these results consists of classes distinguished by their combinations of VNIR, SWIR, and LWIR endmember abundances. The distributions of these integrated classes predominantly correspond to different compositional units and variations within them, and provide greater differentiation than is possible with any one of these spectral ranges alone. Materials that are spatially limited or uncommon within the study region, such as building roofs and REE-bearing phases, are not easily observed in the classification map, which in many cases may be a result of the incorporation of the lower spatial and spectral resolution MASTER LWIR data.

Examination and comparison of Mako LWIR data demonstrates the advantages of hyperspectral LWIR data and suggests that increases in spatial and spectral resolution could improve the classification results from this method. Refinements in the ISODATA cluster analysis integration technique used here, or possibly the use of an alternative method, may also aid in the preservation of compositions with limited occurrence. These observations suggest that further investigation on the topics of hyperspectral LWIR imagery, pixel size, and integration techniques, as well as data co-registration and efficient implementations of complex classification results, could be particularly useful in advancing the application of integrated VNIR-SWIR-LWIR full-range spectral analysis for compositional mapping.

Acknowledgments: We are very thankful to J. Mars from the U.S. Geological Survey for including us in his field work near Mountain Pass and providing spectral ground truth measurements. We are also grateful to S. Adler-Golden of Spectral Sciences Inc., Burlington, MA, USA, and P. Conforti, now at The Aerospace Corporation, for their help and guidance with the FLAASH-IR procedure. Mako imagery was acquired under the auspices of The Aerospace Corporation's Independent Research and Development program.

Author Contributions: M.M. conceived and designed the study with input from F.K.; M.M. performed the analyses; M.M. analyzed and interpreted the results; F.K. advised and assisted with analysis and interpretation; M.M. wrote the manuscript; F.K. reviewed and edited the manuscript.

Conflicts of Interest: The authors declare no conflict of interest.

\section{References}

1. Manolakis, D.; Marden, D.; Shaw, G.A. Hyperspectral Image Processing for Automatic Target Detection Applications. Linc. Lab. J. 2003, 14, 79-116.

2. Xie, Y.; Sha, Z.; Yu, M. Remote sensing imagery in vegetation mapping: A review. J. Plant Ecol. 2008, 1, 9-23. [CrossRef] 
3. Mulder, V.L.; de Bruin, S.; Schaepman, M.E.; Mayr, T.R. The use of remote sensing in soil and terrain mapping-A review. Geoderma 2011, 162, 1-19. [CrossRef]

4. Van der Meer, F.D.; van der Werff, H.M.A.; van Ruitenbeek, F.J.A.; Hecker, C.A.; Bakker, W.H.; Noomen, M.F.; van der Meijde, M.; Carranza, E.J.M.; de Smeth, J.B.; Woldai, T. Multi- and hyperspectral geologic remote sensing: A review. Int. J. Appl. Earth Obs. Geoinf. 2012, 14, 112-128. [CrossRef]

5. Hardin, P.; Hardin, A. Hyperspectral Remote Sensing of Urban Areas. Geogr. Compass 2013, 7, 7-21. [CrossRef]

6. Cudahy, T.J.; Wilson, J.; Hewson, R.; Linton, P.; Harris, P.; Sears, M.; Okada, K.; Hackwell, J.A. Mapping porphyry-skarn alteration at Yerington, Nevada, using airborne hyperspectral VNIR-SWIR-TIR imaging data. In Proceedings of the IEEE 2001 International Geoscience and Remote Sensing Symposium, Sydney, Australia, 9-13 July 2001; pp. 631-633.

7. Kruse, F.A. Combined SWIR and LWIR Mineral Mapping Using MASTER/ASTER. In Proceedings IEEE 2002 International Geoscience and Remote Sensing Symposium, Toronto, ON, Canada, $24-28$ June 2002; pp. 2267-2269.

8. Rowan, L.C.; Mars, J.C. Lithologic mapping in the Mountain Pass, California area using Advanced Spaceborne Thermal Emission and Reflection Radiometer (ASTER) data. Remote Sens. Environ. 2003, 84, 350-366. [CrossRef]

9. Vaughan, R.G.; Calvin, W.M. Synthesis of High-Spatial Resolution Hyperspectral VNIR/SWIR and TIR Image Data for Mapping Weathering and Alteration Minerals in Virginia City, Nevada. In Proceedings of the IEEE 2004 International Geoscience and Remote Sensing Symposium, Anchorage, AK, USA, 20-24 September 2004; pp. 1296-1299.

10. Notesco, G.; Kopačková, V.; Rojík, P.; Schwartz, G.; Livne, I.; Dor, E. Mineral Classification of Land Surface Using Multispectral LWIR and Hyperspectral SWIR Remote-Sensing Data. A Case Study over the Sokolov Lignite Open-Pit Mines, the Czech Republic. Remote Sens. 2014, 6, 7005-7025. [CrossRef]

11. Bowers, T. Analysis of VIS-LWIR hyperspectral image data for detailed geologic mapping. Proc. SPIE 2002, $4725,116-127$.

12. Mustard, J.F.; Cooper, C.D. Joint analysis of ISM and TES spectra: The utility of multiple wavelength regimes for Martian surface studies. J. Geophys. Res. E Planets 2005, 110, 1-13. [CrossRef]

13. Salvatore, M.R.; Mustard, J.F.; Head, J.W.; Rogers, A.D.; Cooper, R.F. The dominance of cold and dry alteration processes on recent Mars, as revealed through pan-spectral orbital analyses. Earth Planet. Sci. Lett. 2014, 404, 261-272. [CrossRef]

14. Goudge, T.A.; Mustard, J.F.; Head, J.W.; Salvatore, M.R.; Wiseman, S.M. Integrating CRISM and TES hyperspectral data to characterize a halloysite-bearing deposit in Kashira crater, Mars. Icarus 2015, 250, 165-187. [CrossRef]

15. Donaldson Hanna, K.L.; Cheek, L.C.; Pieters, C.M.; Mustard, J.F.; Greenhagen, B.T.; Thomas, I.R.; Bowles, N.E. Global assessment of pure crystalline plagioclase across the Moon and implications for the evolution of the primary crust. J. Geophys. Res. Planets 2014, 119, 1516-1545. [CrossRef]

16. Ehsani, A.H.; Quiel, F. Efficiency of Landsat ETM+ Thermal Band for Land Cover Classification of the Biosphere Reserve "Eastern Carpathians" (Central Europe) Using SMAP and ML Algorithms. Int. J. Environ. Res. 2010, 4, 741-750.

17. Abrams, M.; Abbott, E.; Kahle, A. Combined use of visible, reflected infrared, and thermal infrared images for mapping Hawaiian lava flows. J. Geophys. Res. 1991, 96, 475. [CrossRef]

18. Salvatore, M.R.; Mustard, J.F.; Head, J.W.; Marchant, D.R.; Wyatt, M.B. Characterization of spectral and geochemical variability within the Ferrar Dolerite of the McMurdo Dry Valleys, Antarctica: Weathering, alteration, and magmatic processes. Antarct. Sci. 2014, 26, 49-68. [CrossRef]

19. Notesco, G.; Ogen, Y.; Ben-Dor, E. Integration of Hyperspectral Shortwave and Longwave Infrared Remote-Sensing Data for Mineral Mapping of Makhtesh Ramon in Israel. Remote Sens. 2016, 8, 318. [CrossRef]

20. Chen, X.; Warner, T.A.; Campagna, D.J. Integrating visible, near-infrared and short-wave infrared hyperspectral and multispectral thermal imagery for geological mapping at Cuprite, Nevada. Remote Sens. Environ. 2007, 110, 344-356. [CrossRef] 
21. Warner, T.A.; Nerry, F. Does single broadband or multispectral thermal data add information for classification of visible, near- and shortwave infrared imagery of urban areas? Int. J. Remote Sens. 2009, 30, 2155-2171. [CrossRef]

22. Chen, X.; Warner, T.A.; Campagna, D.J. Integrating visible, near-infrared and short-wave infrared hyperspectral and multispectral thermal imagery for geological mapping at Cuprite, Nevada: A rule-based system. Int. J. Remote Sens. 2010, 31, 1733-1752. [CrossRef]

23. Kruse, F.A. Integrated visible and near-infrared, shortwave infrared, and longwave infrared full-range hyperspectral data analysis for geologic mapping. J. Appl. Remote Sens. 2015, 9. [CrossRef]

24. Veraverbeke, S.; Hook, S.J.; Harris, S. Synergy of VSWIR $(0.4-2.5 \mu \mathrm{m})$ and MTIR $(3.5-12.5 \mu \mathrm{m})$ data for post-fire assessments. Remote Sens. Environ. 2012, 124, 771-779. [CrossRef]

25. Cone, S.R.; Kruse, F.A.; McDowell, M.L. Exploration of integrated visible to near-, shortwave-, and longwave-infrared (full range) hyperspectral data analysis. Proc. SPIE 2015, 9472. [CrossRef]

26. McDowell, M.L.; Kruse, F.A. Integrated visible to near infrared, short wave infrared, and long wave infrared spectral analysis for surface composition mapping near Mountain Pass, California. Proc. SPIE 2015, 9472. [CrossRef]

27. Boardman, J.W.; Kruse, F.A. Analysis of Imaging Spectrometer Data Using N-Dimensional Geometry and a Mixture-Tuned Matched Filtering Approach. IEEE Trans. Geosci. Remote Sens. 2011, 49, 4138-4152. [CrossRef]

28. Vaughan, R.G.; Hook, S.J.; Calvin, W.M.; Taranik, J.V. Surface mineral mapping at Steamboat Springs, Nevada, USA, with multi-wavelength thermal infrared images. Remote Sens. Environ. 2005, 99, 140-158. [CrossRef]

29. Schmidt, K.M.; McMackin, M. Preliminary Surficial Geologic Map of the Mesquite Lake 30' $\times 60^{\prime}$ Quadrangle, California and Nevada; U.S. Geological Survey Open-File Report 2006-1035; U.S. Geological Survey: Reston, VA, USA, 2006; p. 89.

30. Mars, J.C.; Rowan, L.C. Spectral assessment of new ASTER SWIR surface reflectance data products for spectroscopic mapping of rocks and minerals. Remote Sens. Environ. 2010, 114, 2011-2025. [CrossRef]

31. Geology and Mineral Resources of the East Mojave National Scenic Area, San Bernardino County, California; U.S. Geological Survey Bulletin 2160; U.S. Geological Survey: Menlo Park, CA, USA, 2007.

32. Hewett, D.F. Geology and Mineral Resources of the Ivanpah Quadrangle California and Nevada; Geological Survey Professional Paper 275; United States Government Printing Office: Washington, DC, USA, 1956.

33. Olson, J.C.; Shawe, D.R.; Pray, L.C.; Sharp, W.N. Rare-Earth Mineral Deposits of the Mountain Pass District San Bernardino County California; Geological Survey Professional Paper 261; United States Government Printing Office: Washington, DC, USA, 1954.

34. Castor, S.B. The Mountain Pass rare-earth carbonatite and associated ultrapotassic rocks, California. Can. Mineral. 2008, 46, 779-806. [CrossRef]

35. Green, R.O.; Eastwood, M.L.; Sarture, C.M.; Chrien, T.G.; Aronsson, M.; Chippendale, B.J.; Faust, J.A.; Pavri, B.E.; Chovit, C.J.; Solis, M.; et al. Imaging spectroscopy and the Airborne Visible/Infrared Imaging Spectrometer (AVIRIS). Remote Sens. Environ. 1998, 65, 227-248. [CrossRef]

36. Hook, S.J.; Myers, J.J.; Thome, K.J.; Fitzgerald, M.; Kahle, A.B. The MODIS/ASTER airborne simulator (MASTER)—A new instrument for earth science studies. Remote Sens. Environ. 2001, 76, 93-102. [CrossRef]

37. Hall, J.L.; Boucher, R.H.; Gutierrez, D.J.; Hansel, S.J.; Kasper, B.P.; Keim, E.R.; Moreno, N.M.; Polak, M.L.; Sivjee, M.G.; Tratt, D.M.; et al. First flights of a new airborne thermal infrared imaging spectrometer with high area coverage. Proc. SPIE 2011, 8012. [CrossRef]

38. Warren, D.W.; Boucher, R.H.; Gutierrez, D.J.; Keim, E.R.; Sivjee, M.G. MAKO: A high-performance, airborne imaging spectrometer for the long-wave infrared. Proc. SPIE 2010, 7812. [CrossRef]

39. Matthew, M.W.; Adler-Golden, S.M.; Berk, A.; Felde, G.W.; Anderson, G.P.; Gorodetzky, D.; Paswaters, S.E.; Shippert, M. Atmospheric correction of spectral imagery: Evaluation of the FLAASH algorithm with AVIRIS data. Proc. SPIE 2003, 5093. [CrossRef]

40. Griffin, M.K.; Burke, H.K. Compensation of Hyperspectral Data for Atmospheric Effects. Linc. Lab. J. 2003, 14, 29-54.

41. Perkins, T.; Adler-Golden, S.; Matthew, M.; Berk, A.; Anderson, G.; Gardner, J.; Felde, G. Retrieval of atmospheric properties from hyper- and multi-spectral imagery with the FLAASH atmospheric correction algorithm. Proc. SPIE 2005, 5979. [CrossRef] 
42. Boardman, J.W. Mineralogic and geochemical mapping at Virginia City, Nevada using 1995 AVIRIS data. In Proceedings of the Twelfth Thematic Conference on Geologic Remote Sensing, Denver, CO, USA, 17-19 November 1997; pp. 21-28.

43. Boardman, J.W. Post-ATREM Polishing of AVIRIS Apparent Reflectance Data using EFFORT: A Lesson in Accuracy versus Precision. In Proceedings of the Summaries of the Seventh JPL Airborne Earth Science Workshop, Pasadena, CA, USA, 12-16 January 1998.

44. Roberts, D.A.; Yamaguchi, Y.; Lyon, R.J.P. Calibration of Airborne Imaging Spectrometer data to precent reflectance using field spectral measurements. In Proceedings of the 19th International Symposium on Remote Sensing of Environment, Ann Arbor, MI, USA, 21 October 1985.

45. Smith, G.M.; Milton, E.J. The use of the empirical line method to calibrate remotely sensed data to reflectance. Int. J. Remote Sens. 1999, 20, 2653-2662. [CrossRef]

46. Young, S.J. An in-scene method for atmospheric compensation of thermal hyperspectral data. J. Geophys. Res. 2002, 107, 4774. [CrossRef]

47. DiStasio, R.J., Jr.; Resmini, R.G. Atmospheric Compensation of Thermal Infrared Hyperspectral Imagery with the Emissive Empirical Line Method and the In-Scene Atmospheric Compensation Algorithms: A Comparison. Proc. SPIE 2010, 7695. [CrossRef]

48. Gillespie, A.; Rokugawa, S.; Matsunaga, T.; Cothern, J.S.; Hook, S.; Kahle, A.B. A temperature and emissivity separation algorithm for Advanced Spaceborne Thermal Emission and Reflection Radiometer (ASTER) images. IEEE Trans. Geosci. Remote Sens. 1998, 36, 1113-1126. [CrossRef]

49. Adler-Golden, S.M.; Conforti, P.; Gagnon, M.; Tremblay, P.; Chamberland, M. Long-wave infrared surface reflectance spectra retrieved from Telops Hyper-Cam imagery. Proc. SPIE 2014, 9088. [CrossRef]

50. Keshava, N. A Survey of Spectral Unmixing Algorithms. Linc. Lab. J. 2003, 14, 55-78.

51. Plaza, A.; Du, Q.; Bioucas-Dias, J.M.; Jia, X.; Kruse, F.A. Foreword to the Special Issue on Spectral Unmixing of Remotely Sensed Data. IEEE Trans. Geosci. Remote Sens. 2011, 49, 4103-4110. [CrossRef]

52. Green, A.A.; Berman, M.; Switzer, P.; Craig, M.D. A transformation for ordering multispectral data in terms of image quality with implications for noise removal. IEEE Trans. Geosci. Remote Sens. 1988, 26, 65-74. [CrossRef]

53. Boardman, J.W.; Kruse, F.A.; Green, R.O. Mapping target signatures via partial unmixing of AVIRIS data. In Proceedings of the Summaries of the 5th Annunal JPL Airborne Earth Science Workshop, Pasadena, CA, USA, 23-26 January 1995; pp. 23-26.

54. Boardman, J.W. Automated spectral unmixing of AVIRIS data using convex geometery concepts. In Proceedings of the Summaries of the 4th JPL Airborne Geoscience Workshop, Washington, DC, USA, 25-29 October 1993; pp. 11-14.

55. Boardman, J.W. Leveraging the high dimensionality of AVIRIS data for improved sub-pixel target unmixing and rejection of false positives: mixture tuned matched filtering. In Proceedings of the Summaries of the 7th JPL Airborne Earth Science Workshop, Pasadena, CA, USA, 12-16 January 1998; p. 55.

56. Thompson, D.R.; Mandrake, L.; Green, R.O.; Chien, S.A. A case study of spectral signature detection in multimodal and outlier-contaminated scenes. IEEE Geosci. Remote Sens. Lett. 2013, 10, 1021-1025. [CrossRef]

57. Kruse, F.A.; Baugh, W.M.; Perry, S.L. Validation of DigitalGlobe WorldView-3 Earth imaging satellite shortwave infrared bands for mineral mapping. J. Appl. Remote Sens. 2015, 9. [CrossRef]

58. Chen, J.Y.; Reed, I.S. A Detection Algorithm for Optical Targets in Clutter. IEEE Trans. Aerosp. Electron. Syst. 1987, 1, 46-59. [CrossRef]

59. North, D.O. An Analysis of the Factors which Determine Signal/Noise Discrimination in Pulsed-Carrier Systems. Proc. IEEE 1963, 51, 1016-1027. [CrossRef]

60. Tou, J.T.; Gonzalez, R.C. Pattern Recognition Principles; Addison-Wesley Publishing Company: Reading, PA, USA, 1974.

61. Clark, R.N.; Swayze, G.A.; Wise, R.; Livo, E.; Hoefen, T.; Kokaly, R.; Sutley, S.J. USGS Digital Spectral Library Splib06a; U.S. Geological Survey Data Series 231; U.S. Geological Survey: Denver, CO, USA, 2007; Volume 231.

62. Baldridge, A.M.; Hook, S.J.; Grove, C.I.; Rivera, G. The ASTER spectral library version 2.0. Remote Sens. Environ. 2009, 113, 711-715. [CrossRef]

63. Turner, D.J.; Rivard, B.; Groat, L.A. Visible and short-wave infrared reflectance spectroscopy of REE fluorocarbonates. Am. Mineral. 2014, 99, 1335-1346. [CrossRef] 
64. Clark, R.N.; King, T.V.V.; Klejwa, M.; Swayze, G.A. High spectral resolution reflectance spectroscopy of minerals. J. Geophys. Res. 1990, 95, 12653-12680. [CrossRef]

65. Clark, R.N. Chapter 1: Spectroscopy of Rocks and Minerals, and Principles of Spectrosocopy. In Manual of Remote Sensing, Volume 3, Remote Sensing for the Earth Sciences; Rencz, A.N., Ed.; John Wiley and Sons: New York, NY, USA, 1999; pp. 3-58.

66. Duke, E.F. Near infrared spectra of muscovite, Tschemak substitution, and metamorphic reaction progress: Implications for remote sensing. Geology 1994, 22, 621-624. [CrossRef]

67. Ribeiro da Luz, B.; Crowley, J.K. Spectral reflectance and emissivity features of broad leaf plants: Prospects for remote sensing in the thermal infrared $(8.0-14.0 \mu \mathrm{m})$. Remote Sens. Environ. 2007, 109, 393-405. [CrossRef]

68. Kohonen, T. Self-Organizing Maps; Springer: Berlin, Germany, 2001.

69. Liu, Y.; Weisberg, R.H. A Review of Self-Organizing Map Applications in Meteorology and Oceanography. In Self Organizing Maps—Applications and Novel Algorithm Design; Mwasiagi, J.I., Ed.; InTech: Rijeka, Croatia, 2011; pp. 253-272.

70. Liu, Y.; Weisberg, R.H.; Vignudelli, S.; Mitchum, G.T. Patterns of the loop current system and regions of sea surface height variability in the eastern Gulf of Mexico revealed by the self-organizing maps. J. Geophys. Res. Ocean. 2016, 121, 2347-2366. [CrossRef]

71. Awad, M. An unsupervised artificial neural network method for satellite image segmentation. Int. Arab J. Inf. Technol. 2010, 7, 199-205.

72. Duran, O.; Petrou, M. A time-efficient method for anomaly detection in hyperspectral images. IEEE Trans. Geosci. Remote Sens. 2007, 45, 3894-3904. [CrossRef]

73. Merényi, E.; Csatho, B.; Tasdemir, K. Knowledge discovery in urban environments from fused multi-dimentional imagery. In Proceedings of the 4th IEEE GRSS/ISPRS Joint Workshop on Remote Sensing and Data Fusion over Urban Areas, Paris, France, 11-13 April 2007; pp. 1-13.

(C) 2016 by the authors; licensee MDPI, Basel, Switzerland. This article is an open access article distributed under the terms and conditions of the Creative Commons Attribution (CC-BY) license (http://creativecommons.org/licenses/by/4.0/). 